Florida International University FIU Digital Commons

7-15-1994

\title{
The effects of laboratory-induced mood on secretory immunoglobulin A in saliva
}

Susan Strum Dubitsky

Florida International University

DOI: $10.25148 /$ etd.FI15101234

Follow this and additional works at: https://digitalcommons.fiu.edu/etd

Part of the Psychology Commons

\section{Recommended Citation}

Dubitsky, Susan Strum, "The effects of laboratory-induced mood on secretory immunoglobulin A in saliva" (1994). FIU Electronic Theses and Dissertations. 3091.

https://digitalcommons.fiu.edu/etd/3091 
FLORIDA INTERNATIONAL UNIVERSITY

Miami, Florida

\title{
THE EFFECTS OF LABORATORY INDUCED MOOD ON SECRETORY IMMUNOGLOBULIN A IN SALIVA
}

\author{
A dissertation submitted in partial satisfaction of the \\ requirements for the degree of \\ DOCTOR OF PHILOSOPHY \\ IN \\ PSYCHOLOGY \\ by
}

Susan Strum Dubitsky

1994 
To: Arthur W. Herriott

College of Arts and Sciences

This dissertation, written by Susan Strum Dubitsky, and entitled The Effects of Laboratory Induced Mood on Secretory Immunoglobulin A in Saliva, having been approved in respect to style and intellectual content, is referred to you for judgement.

We have read this dissertation and recommend that it be approved.

Barry Crown

Brian L. Cutler

L. Scott Quackenbush

James G. Rotton, Major Professor

Date of Defense: July 15, 1994

This dissertation of Susan Strum Dubitsky is approved.

Dean Arthur W. Herriott

College of Arts and Sciences

Dr. Richard L. Campbell

Dean of Graduate Studies

Florida International University, 1994 
${ }^{\circledR}$ COPYRIGHT 1994 by Susan Strum Dubitsky

All rights reserved 
I dedicate this dissertation to my husband, Larry. Without his patience, understanding, support, and most of all love, the completion of this work would not have been possible. 


\section{ACKNOWLEDGMENTS}

I wish to thank the members of my committee for their support. In particular, I want to thank Dr. Scott Quackenbush for his infinite patience in trying to turn a psychologist into a biochemist. This project could never have been completed without Dr. Quackenbush's allowing me free reign in his laboratory.

I want to thank all the undergraduate assistants who gave of themselves wholeheartedly. Rob Schendowich, Naima K. Ghany, and Lynn Herndon were among the students whose dedication and sense of responsibility were outstanding.

Thanks, too, to my dear friend Ruth Weber, whose support and loyalty kept me going. My husband, Larry, deserves a medal for putting up with me through graduate school.

A special thanks must go to my major professor, Dr. Rotton, for having the confidence in me to give me the chance to do this project. 


\title{
ABSTRACT OF THE DISSERTATION \\ THE EFFECTS OF LABORATORY INDUCED MOOD \\ ON SECRETORY IMMUNOGLOBULIN A IN SALIVA
}

by

\author{
Susan Strum Dubitsky \\ Florida International University, 1994 \\ Dr. James G. Rotton, Major Professor
}

The effects of induced mood on secretory immunoglobulin A (SIgA) were tested on 104 students (51 men \& 53 women) using a mixed design with between subject factors of gender, induced mood (positive vs. negative), method of induction (writing about oneself vs. viewing a video), and a within subject factor, time (baseline vs. posttest). A split-plot multivariate analysis of covariance, controlling for salivary flow rate, did not support a causal link between induced mood alone and change in SIgA concentration. The effect of induced mood on blood pressure and heart rate was also examined. There were no significant main effects, but gender interacted with mood induction such that females experienced an increase in blood pressure in the positive mood induction condition. There was no significant effect of method of mood induction on SIgA, blood pressure, or heart rate. Stable personality traits, however, moderated the effects of mood induction. Persons who scored higher on depression and neuroticism, and lower on positive affect had significantly higher SIgA concentrations in the negative mood condition. There were no significant effects of 
personality traits on SIgA levels in the positive mood condition, nor did they interact with induced mood to change blood pressure or heart rate. These data suggest that although SIgA concentration may not be subject to short-term laboratory mood manipulations alone, changes in SIgA concentration may be associated with an interaction of stable personality traits and mood state, especially in the case induced negative mood. 


\section{TABLE OF CONTENTS}

PAGE

INTRODUCTION $\ldots \ldots \ldots \ldots \ldots \ldots \ldots \ldots \ldots \ldots \ldots \ldots \ldots$

Psychosocial Factors Associated with Elevated SIgA Concentrations . . . 3

Factors Associated with Decreased SIgA Concentrations . . . . . . . . 4

Methodological Issues in SIgA Studies $\ldots \ldots \ldots \ldots \ldots \ldots \ldots$

Aims and Objectives $\ldots \ldots \ldots \ldots \ldots \ldots \ldots \ldots \ldots \ldots$

Hypotheses ........................... 9

METHOD ............................ 10

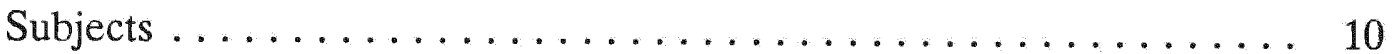

Personality Variables $\ldots \ldots \ldots \ldots \ldots \ldots \ldots \ldots \ldots \ldots \ldots \ldots$

Introversion-Extroversion/Neuroticism Scale $\ldots \ldots \ldots \ldots \ldots 11$

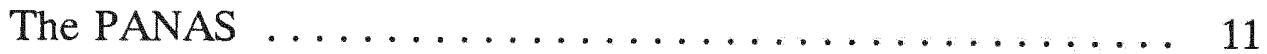

Life Orientation Test ................. 11

Dissipation-Rumination Scale . . . . . . . . . . . 11

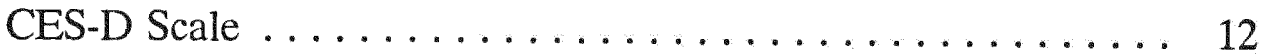

Physiological Variables . . . . . . . . . . . . . . . . 12

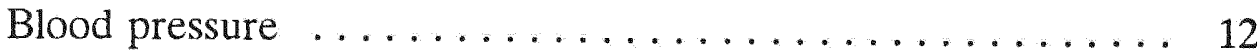

Saliva collection $\ldots \ldots \ldots \ldots \ldots \ldots \ldots \ldots \ldots \ldots \ldots \ldots$

Manipulations $\ldots \ldots \ldots \ldots \ldots \ldots \ldots \ldots \ldots \ldots \ldots \ldots \ldots$

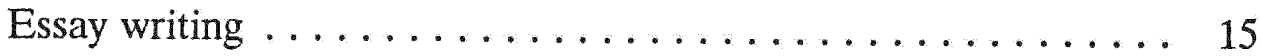

Video viewing $\ldots \ldots \ldots \ldots \ldots \ldots \ldots \ldots \ldots \ldots \ldots \ldots$ 
Dependent Variables $\ldots \ldots \ldots \ldots \ldots \ldots \ldots \ldots \ldots \ldots$

Saliva Assay . . . . . . . . . . . . . . . . . . . 17

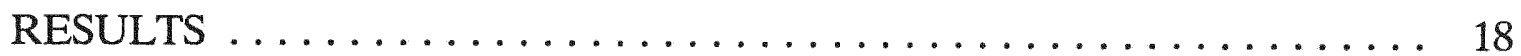

Preliminary Analyses $\ldots \ldots \ldots \ldots \ldots \ldots \ldots$

Group equivalence $\ldots \ldots \ldots \ldots \ldots \ldots \ldots \ldots \ldots$

Gender .......................... 20

Reliability Analyses $\ldots \ldots \ldots \ldots \ldots \ldots \ldots \ldots \ldots$

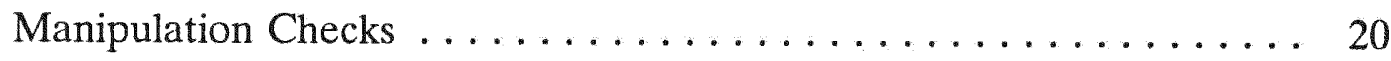

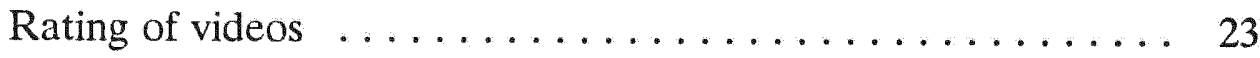

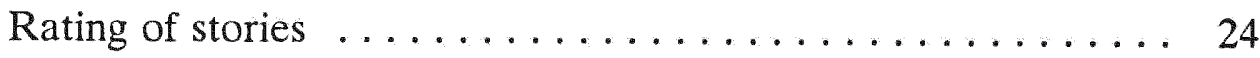

Experimental Findings $\ldots \ldots \ldots \ldots \ldots \ldots \ldots \ldots \ldots \ldots$

Blood Pressure and Heart Rate ............. 27

Moderator Regression Variables . . . . . . . . . . . . . . . 29

Mediational Analyses . . . . . . . . . . . . . . . 34

Subsidiary Analysis . . . . . . . . . . . . . . . . . 34

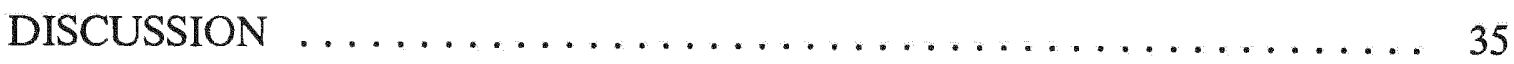

Hypotheses Concerning Blood Pressure and Heart Rate . . . . . . . 37

The Role of Stable Personality Traits and Immunology . . . . . . . 38

Depression and immunity . . . . . . . . . . . . . . . 39

Neuroticism and health $\ldots \ldots \ldots \ldots \ldots \ldots \ldots \ldots$

Chronic versus Situational Stressors and SIgA . . . . . . . . 41

Conclusions $\ldots \ldots \ldots \ldots \ldots \ldots \ldots \ldots \ldots \ldots \ldots \ldots \ldots \ldots \ldots$ 


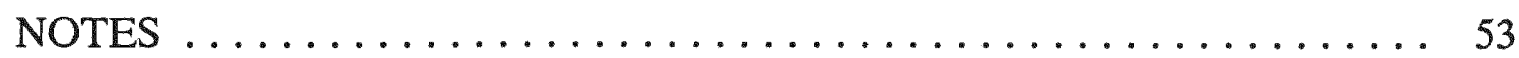

APPENDICES ......................... 56

Appendix A: Personality Variables $\ldots \ldots \ldots \ldots \ldots \ldots \ldots 6$

Introversion-Extroversion/Neuroticism Scale $\ldots \ldots \ldots \ldots 7$

The PANAS $\ldots \ldots \ldots \ldots \ldots \ldots \ldots \ldots \ldots \ldots \ldots$

Life Orientation Test ................ 60

Dissipation-Rumination Scale . . . . . . . . . . . 61

Center for Disease Control-Depression Scale . . . . . . . 63

Appendix B: Informed Consent Form $\ldots \ldots \ldots \ldots \ldots \ldots$

Appendix C: General Health Inventory . . . . . . . . . 68

Appendix D: Suggested Topics for Mood Induction by Writing . . . 72

Appendix E: Video Rating Form $\ldots \ldots \ldots \ldots \ldots \ldots \ldots \ldots$

Appendix F: Symptom/Emotion Checklist . . . . . . . . 77

Appendix G: Anonymous Evaluation of Research Assistants . . . . 79

Appendix $\mathrm{H}:$ Debriefing Form $\ldots \ldots \ldots \ldots \ldots \ldots$

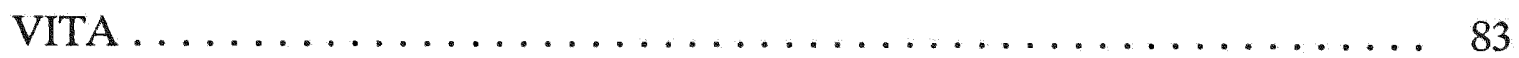




\section{LIST OF TABLES}

PAGE

Table 1. Means and Standard Deviations of the Ratings of Characteristics of the Two Videotapes Used to Induce Mood . . 23

Table 2. Means and Standard Deviations of Ratings of Negative and Positive Stories Written to Induce Mood ........... 25

Table 3. Results of Moderator Regressions Used to Test for Interactions Between Personality Traits and Valence of Mood Induction as Predictors of Secretory Immunoglobulin A Concentration . . . . 29

Table 4. Standard Deviations and Regression Coefficients Used to Plot the Significant Interactions in the Moderator Regression

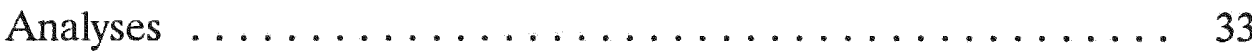




\section{LIST OF FIGURES}

PAGE

Figure 1. The Mean Number of Self-Reported Negative Emotions and Physical Symptoms by Valence of Induced Mood and Method

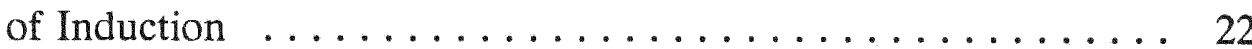

Figure 2. Changes in Concentration of Secretory Immunoglobulin A After Inducing Positive or Negative Mood Using Two Methods of Induction: Watching a Videotape or Writing an Essay $\ldots . .26$

Figure 3. The Effect of Positive and Negative Mood Induction on Blood Pressure for a Sample of Male and Female College Students . . 28

Figure 4. Plots of Simple Slopes for Moderator Regression Interactions . 32 
The Effects of Laboratory Induced Mood

on Secretory Immunoglobulin A in Saliva

The emerging field of psychoneuroimmunology can be traced to the serendipitous conditioning of a rat's immune system by Ader and Cohen (1975). Using a classic Pavlovian conditioning paradigm, Ader and Cohen conditioned rats to develop an aversion to saccharin. Aversion was achieved via the administration of cyclophosphamide, a drug that produces nausea and vomiting. During the extinction phase of the experiment, when the drug was no longer administered, the rats kept dying. Ader and Cohen, in reviewing their procedures to determine the cause for this phenomenon, discovered that a side-effect of cyclophosphamide was immunosuppression. A series of controlled, follow-up studies replicated the findings; rats continued to suppress their immune systems even when cyclophosphamide was withdrawn (Ader \& Cohen, 1981).

Several introductions to the basic concepts of psychoneuroimmunology (Camara \& Danao, 1989; Daruna \& Morgan, 1990; Geiser, 1989; Kemeny, Solomon, Morley, \& Herbert, 1992) and quite a few reviews of the literature have been published since Ader and Cohen's discovery (e.g., Jemmott \& Locke, 1984; KiecoltGlaser \& Glaser, 1988, 1989; O'Leary, 1990; Weisse, 1992). The literature in this area was extensive enough to warrant four meta-analyses (Herbert \& Cohen, 1993a; 1993b; Jemmott \& McClelland, 1989; Van Rood, Bogaards, Goulmay, \& van Houwelingen, 1993). 
The present study was concerned primarily with the relation between psychological factors and one component of the immune system, secretory immunoglobulin A (SIgA). SIgA is found in all of the body's secretory fluids including saliva, nasal, gastrointestinal, and vaginal secretions. Immunoglobulin A (IgA) is found also in blood. IgA is one of the classes of antibodies secreted by B cells. Its function is to deter infection by adhering to the surface of cells and thus prevent entry of pathogens (Roitt, 1988). Stone, Reed, and Neale (1987) suggested that SIgA may be a mediating mechanism between stressful events and the onset of flu and cold symptoms that frequently appear three to five days after a stressful experience.

IgA also has a memory component that protects against reinfection by pathogens that caused previous infections (Greenberg, 1989). Although some sources report that people with a chronic deficiency of SIgA suffer from an increased incidence of upper respiratory and sinus infections (Kallestad Laboratories, Inc., 1984; Kubitz, Peavey, \& Moore, 1986), other sources indicate that this is not the case (Widmann, 1989).

Two studies have demonstrated a relation between SIgA concentrations and the presence of upper respiratory infections (URI). McClelland, Alexander, and Marks (1982) found that low SIgA concentrations were related to the occurrence of URI in prison inmates. Yodfat and Silvian (1977) found that the ability to secrete large amounts of SIgA while one has an URI is related to decreased overall 
occurrences of such infections. However, Cohen, Tyrell and Smith (1991) failed to find any evidence to support the idea that SIgA is related to the onset of URIs.

To summarize, the extent to which SIgA serves a protective function in the immune system is unclear (Widman, 1989). However, several psychological studies have documented that SIgA responds to both short and long term psychosocial variables such as stress, mood induction, and relaxation.

\section{Psychosocial Factors Associated with Elevated SIgA Concentrations}

The results of a meta-analysis conducted by Van Rood et al. (1993), although inconclusive for the effects of stress on SIgA, proved highly supportive for a link between SIgA and relaxation or positive affect inducing factors. For example, subjects who used guided imagery had significant increases in SIgA concentrations compared to subjects who listened to music or who were in a control condition with no music or imagery (Rider, Achterberg, Lawlis, Goven, Toledo \& Butler, 1990). In a study by Green and Green (1987), subjects who had undergone any of four different relaxation treatments had higher SIgA concentrations at the end of 20minute relaxation sessions than those in a control group. In a follow-up study, Green, Green, and Santoro (1988) randomly assigned subjects to one of three relaxation training groups or a control "waiting list" condition for a three-week period. At the end of the three weeks, subjects in all of the relaxation conditions had higher SIgA concentrations than the controls.

Similar findings were reported in a study by Olness, Culbert, and Uden (1989). Children aged 6-12 years were assigned to one of three groups including (a) listening 
to a self-hypnosis relaxation tape, (b) listening to the self-hypnosis relaxation tape with the addition of instructions to imagine their immune systems being strong and healthy, and (c) a control group. The children in the relaxation plus instructions group had higher SIgA concentrations at the end of the 25-minute treatment period. The results of this study suggest that positive imagery concerning the immune system actually enhances the immune system.

Humor also has been shown to be associated with significant increases in SIgA concentrations. Dillon, Minchoff, and Baker (1985) found that subjects who viewed a humorous movie had higher SIgA concentrations after viewing the movie compared to baseline pre-movie-viewing concentrations. Vela (1990) obtained similar findings. Additionally, Martin and Dobbin (1988) found sense of humor, as a trait, was a moderator between daily hassles and levels of SIgA.

In a study designed to increase subjects' sense of affiliation, McClelland and Krishnit (1988) found that those who viewed a movie about the work of Mother Theresa had higher SIgA concentrations after than before viewing the one-hour movie.

\section{Factors Associated with Decreased SIgA Concentrations}

Both negative affect and stress have been found to be associated with depressed levels of SIgA. For example, in a 1987 study by Stone, Cox, Valdimarsdottir, Jandorf, and Neale (1987), subjects had significantly lower SIgA concentrations on days when they had higher levels of self-reported negative mood. 
Kubitz et al. (1986) studied the effects of daily hassles and personality factors on SIgA. Their results indicate an inverse relation between SIgA and internal health locus of control. The more control that people indicated they had over whether or not they got sick, the lower were their SIgA levels. The amount of stress that people experienced, in the form of daily hassles, was not related to SIgA levels, however, internal health locus of control interacted with daily hassles, such that people having both high stress and a high degree of internality (control) had lower SIgA concentrations than people with high stress and low internality.

Mouton, Fillion, Tawadros, and Tessier (1989) observed that SIgA concentrations in saliva drawn from subjects at the time of final examinations were significantly lower than that in saliva taken just after return from summer vacation. Their study also revealed a significant inverse relation between self-reported stress and SIgA concentration at the time of final examinations: high levels of distress were associated with lower SIgA concentrations. Similarly, Jemmott and Magliore (1988) found marked decrements in subjects' SIgA levels during final examinations compared to non-examination periods during the course of the school year. There is some reason to believe that relations between examination stress and SIgA are moderated by a subject's need for power (Jemmott et al., 1983; 1990; McClelland, Floor, Davidson, \& Saron, 1980; McClelland, Ross, \& Patel, 1985). Jemmott, et al. and McClelland et al. have found that decreases in SIgA resulting from examination stress were significantly greater for individuals' exhibiting inhibited power motivation syndrome. Inhibited power motivation is found in individuals who 
crave power, but who inhibit their expression of this need. However, research concerning "inhibited power motivation syndrome" has been criticized because SIgA levels are subject to shifts in mood and an alternative explanation is that mood shift, rather than "inhibited power motivation syndrome" is responsible for changes in SIgA concentration (Stone, Cox, Valdimarsdottir, Jandorf, \& Neale, 1987).

The findings concerning stress and decreased levels of SIgA were not borne out in a study by Kiecolt-Glaser, Garner, Speicher, Penn, Holliday and Glaser (1984). Kiecolt-Glaser et al. investigated the effects of both loneliness and examination stress on several measures of immune competence including natural killer cell functioning (NK) and IgA levels both in serum and in saliva. These researchers demonstrated that both loneliness and examination stress had a suppressive effect on NK functioning in a sample of medical students. The surprising finding was that IgA was significantly higher in blood samples taken just prior to the time of examination than those found in baseline samples. Salivary IgA levels did not show a corresponding increase in concentration, nor did they show the decrease cited by other research groups.

Herbert \& Cohen in their 1993 b meta-analysis found an overall significant inverse relation between stress and SIgA level, however, when they reanalyzed their data correcting for flow rate (see below), they found that the relation between stress and SIgA concentration disappeared. Because many of the studies included in the Herbert and Cohen study did not control for flow rate, it is difficult to know whether this finding is due to the fact that fewer studies were included in the reanalysis or 
to removing the effect of flow rate (particularly because the direction of the relations among SIgA concentration, stress, and flow rate suggest that controlling for flow rate would increase the magnitude of the relation between stress and SIgA).

\section{Methodological Issues in SIgA Studies}

Some of the findings cited above are clouded by methodological issues involved in SIgA research, in particular, the inclusion of salivary flow rate in any data analyses. Brandtzaeg (1971) reported an inverse relation between rate of salivary flow and SIgA concentrations. Aufricht, Tenner, Salzer, Khoss, Wurst, and Herkner (1992) corroborated this finding, but only in samples obtained through expectoration.

Others have shown that there is a relation between stress and/or anxiety and decreased salivary flow ("dry mouth") (Bates \& Adams, 1968; Jemmott \& Magliore, 1988; Talbott, Hales, \& Yudofsky, 1988). What this means is that any increases or decreases in SIgA concentrations attributed to differences in mood may be due to changes in salivary flow, especially in those studies that use some form of expectoration as the collection procedure. Although some researchers believe that SIgA levels present in saliva "are dependent on flow rate" (Kiecolt-Glaser et al., 1984), other researchers have shown that taking flow rate into account did not alter the results of their analyses (McClelland \& Krishnit, 1988).

The efficacy of using SIgA as a measure of immune functioning has previously been addressed in the literature (Jemmott \& McClelland, 1989; Stone, Cox, Valdimarsdottir, \& Neale, 1987). Stone and colleagues cautioned that although SIgA is relatively easy to obtain and assay (via readily obtainable radial immunodiffusion 
kits) factors such as inappropriate collection procedures or inadequately controlling for flow rate can affect the interpretation and application of results. Jemmott and McClelland recommended using analysis of covariance to partial out flow rate in order to assess exact levels of SIgA present in each saliva sample.

\section{Aims and Objectives}

The present study was an attempt to determine the extent of SIgA responsiveness to laboratory induced positive or negative mood and to validate this responsiveness across two different mood induction methods while controlling for salivary flow rates. The two methods of mood induction used were: writing about one's life experiences and viewing a videotape. Secondary physiological dependent measures were blood pressure and pulse. The interaction of stable personality characteristics with valence of mood induction was tested via moderator regression analyses. The independent variables in a four-factor design were gender, mood induction (positive vs. negative), method of induction (writing about oneself or viewing a videotape), and time (baseline and posttest measures), with time as a within subject factor, and gender, mood and method as the between subject factors.

This study served as a test of the relative strength of two methods of mood induction. The methods had different points of focus. Writing about personal experiences makes "the self" the center of attention. Watching a videotape of strangers is an impersonal act. The focus of attention is "other-centered." The question that arose was which focus (self vs. other) produces the greatest amount of arousal and/or change in mood. 
As previously noted, research has shown that funny or inspirational movies can precipitate increases in SIgA concentrations (Dillon et al., 1986; McClelland \& Krishnit, 1988; Vela, 1990). The effect of viewing negative affect inducing movies on SIgA is unclear at this point. Dillon et al. (1986) used a "boring" movie-control condition. Vela's (1990) control subjects watched a "serious" movie. McClelland and Krishnit (1988) used a movie that was supposed to instill feelings of power in the people who watched it; feelings of power, in turn, would then drive down SIgA concentrations. The manipulation was successful only for people who exhibited a syndrome McClelland calls "inhibited power motivation syndrome." Research by Isen and colleagues (Isen \& Daubman, 1984, Isen \& Gorglione, 1983) has shown that watching negative affect-inducing movies produces increases in negative affect as measured by self-report data. Because the present study closely followed Isen and Gorglione's (1983) method, it served as a test of whether physiological states are related to self-report measures of affectivity.

\section{Hypotheses}

The principle hypothesis of this study was:

H1. SIgA concentration increases in conditions that induce positive mood and decreases in conditions that induce negative mood.

Subsidiary hypotheses were:

H2. Negative mood induction increases blood pressure and pulse rate.

H3. The focus (method) of mood induction does not affect outcomes of physiological measures. 
It also was anticipated that relations between mood induction and SIgA will be moderated by positive and negative personality characteristics. Positive characteristics are defined by trait positive affect, optimism, and extraversion. Negative characteristics are defined by trait negative affect, depression, neuroticism and rumination (the tendency to hold grudges). The following hypotheses were tested concerning these characteristics:

H4. Positive personality characteristics enhance the beneficial physiological outcomes in positive mood conditions, that is, further raise SIgA levels and lower blood pressure and heart rate.

H5. Positive personality characteristics buffer the deleterious physiological outcomes in the negative mood conditions.

H6. Negative personality characteristics impede the beneficial physiological outcomes in the positive mood conditions.

H7. Negative personality characteristics exacerbate the deleterious physiological outcomes in the negative mood conditions, that is, further lower SIgA levels and increase blood pressure and heart rate.

\section{Method}

\section{Subjects}

One hundred and eight undergraduate psychology students were recruited to take part in this study. Three males were excused because their baseline blood pressure exceeded the established safety level (Brannon \& Feist, 1992). Data from these subjects are not included in any of the final analyses. The final sample 
consisted of 51 males and 54 females. Their mean age was 21 years $(\mathrm{SD}=4.79)$. Each student was paid $\$ 5.00$ for his or her participation.

Personality Variables

The following scales which are presented in Appendix A were administered to subjects upon their arrival at the laboratory.

Introversion-Extroversion/Neuroticism Scale. This scale measures two aspects of personality, extroversion and neuroticism (Eysenck, 1958). The alpha coefficient for the 6-item neuroticism scale was .70. The alpha coefficient for the 6-item extroversion scale was .37 .

The PANAS. This scale is a self-rating of trait positive and negative affect (Watson, Clark, \& Tellegen, 1988). Subjects are asked to indicate, on a 1 to 5 scale, the extent to which they have felt each one of 20 emotions during the past six months. Frequency anchors used in this study were "not at all, a little, moderately, quite a bit, and extremely." The internal consistency reliability (Cronbach's alpha) obtained in the present study was .87 for both the positive and negative subscales. These alpha levels are consistent with those that have been previously reported.

Life Orientation Test. The Life Orientation Test (LOT) asks respondents to indicate their level of agreement with 12 items; a high score indicates an optimistic disposition (Scheier \& Carver, 1987; Scheier, Weintraub, \& Carver, 1986). The alpha coefficient obtained in this study was .80 .

Dissipation-Rumination Scale. This 20 -item scale was designed to measure the extent to which an individual is likely to hold on to or let go of grudges (Caprara, 
1986). Subjects rate on a 1-5 scale how representative each item is of their own behavior. In the literature, the coefficient alpha reported for this scale ranges from .79 to .87 . In the present study, the obtained alpha level was .83 .

CES-D Scale. The Center for Epidemiologic Studies Depression Scale (CESD Scale) consists of 20 items (Radloff, 1977). Subjects respond on a scale of 1 to 5 the frequency with which they felt "bothered by things that usually don't bother me," or "had trouble keeping my mind on what I was doing." The alpha coefficient obtained in this study was .88 .

Physiological Variables

Blood pressure. Blood pressure and pulse readings were taken at the conclusion of an initial 16-minute resting baseline period, and again at the end of the experimental manipulation using a home quality digital blood pressure meter/pulse monitor (Labtron ${ }^{\mathrm{TM}}$, Graham-Field, Inc., Hauppauge, New York). ${ }^{1}$ The blood pressure meter has a cuff that wraps around a person's arm and is inflated manually with a hand pump. Blood pressure and pulse rate are read from a LCD display. Blood pressure and pulse readings were taken on the left arm of each subject.

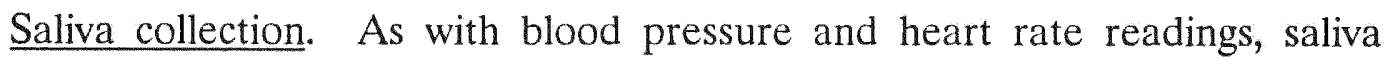
samples were collected after an initial 16-minute resting baseline period and again following the experimental manipulation.

A pilot study had been conducted previously to determine the most appropriate saliva collection procedure to use in this study. The study was prompted by a debate in the literature as to the various factors that affect SIgA concentrations. 
These factors include flow rate, and the use of saliva obtained directly from the parotid and mandibular glands versus saliva present in the oral cavity itself (Jemmott \& McClelland, 1989; Stone, Cox, Valdimarsdottir, Jandorf, \& Neale, 1987; Stone, Cox, Valdimarsdottir, \& Neale, 1987). Based on the results of the pilot study, the Kerr (1961) method of saliva collection was used. Kerr's method allows for saliva to flow free directly from the salivary glands with little contamination from mucosal substances that may be present when samples are obtained via expectoration from the oral cavity (Dubitsky, Weber, \& Rotton, 1993).

Following Kerr's (1961) method, subjects were asked to sit with their heads tilted down and slightly forward to allow saliva to flow freely into a chilled cup. Saliva collection was timed for five minutes. At the end of the five minute period, subjects poured their saliva into a chilled graduated syringe which was used to determine the volume. Recording the volume is necessary to the determination of flow rate. Jemmott and McClelland (1989) have recommended the use of timed saliva samples as a way of insuring accuracy of SIgA concentrations.

The subjects then injected approximately $1 \mathrm{ml}$ of saliva into a prechilled 1.5 $\mathrm{ml}$ Eppendorf ${ }^{\mathrm{TM}}$ tube. The test tubes were labeled with the subject ID number and immediately placed on ice. Saliva samples were then frozen at $-20^{\circ} \mathrm{C}$ and stored at this temperature until they were shipped to the laboratory for assaying. Manipulations

All subjects were contacted the evening before their appointment to remind them to avoid eating or drinking anything for one hour prior to visiting the 
laboratory. Kiecolt-Glaser and Glaser (1988) report these certain behaviors can alter immune cell functioning so that the reliability of these measures is diminished.

After subjects arrived at the laboratory, they were given an informed consent form (see Appendix B), followed by a questionnaire containing the personality scales described above, and the General Health Inventory (GHI), a behavioral health inventory. Questions on the GHI pertain to general health status for the two-week period prior to coming to the laboratory (see Appendix C). There were also questions pertinent to smoking, alcohol and caffeine consumption, and sleep and eating disturbances for the three days prior to the study. (cf., Kiecolt-Glaser \& Glaser, 1988).

After completing the GHI battery, subjects listened to relaxing music through a headset for 16 minutes in order to establish a resting baseline for the collection of physiological data. The tape used, George Winston's "December" (Windham Hill Records, 1982) was previously shown to induce a state of relaxation (Dimsdale, Young, Moore, \& Strauss, 1987). To enhance the attainment of a relaxed state subjects were seated in an upholstered chair in a dimly lit room that had been decorated with soothing watercolor paintings. Room settings have been shown to affect subjects feelings of relaxation and self-disclosure (Chaikin, Derlaga, \& Miller, 1976). This was done to maximize the effects of the writing manipulation used in this study. Once the subjects were seated comfortably and the headset was in place, the experimenters left the room for the duration of the tape. Baseline saliva samples, 
blood pressure, and heart rate recordings were taken at the end of the 16-minute period.

Following the collection of physiological data, subjects were randomly assigned to one of four experimental conditions: positive or negative writing (self focus) or positive or negative movie viewing (other focus).

Essay writing. Following a methodology employed by Pennebaker and Beall (1986) and Pennebaker, Kiecolt-Glaser and Glaser (1988b), the experimenter told subjects that they would be asked to write about positive [negative] experiences they have encountered in their lives. The experimenter then played the following tape recorded set of instructions designed to set the tone of the writing session:

At sometime in our lives we've all experienced negative [positive] events. We'd like you to recall and write about three experiences which were extremely upsetting to you [extremely pleasing to you]. As you're writing, we'd like you to not only describe the event, but to talk about the kinds of emotions and sensations you felt while you were going through the experience. You will find that as you write, your memories will become clearer and more specific. It will seem as though you are actually reliving the same experience now. You may find it easier to recall the events, feelings and sensations you experienced if you assume the same body posture you were in at the time the events originally occurred. If you find you prefer writing about one or two events, you may do so. You'll have approximately 
half hour in which to write. There's no rush. Please take the entire half hour. No one will be in the room with you and the content of your essays will be coded with an ID number so anything you write will be kept strictly confidential.

The experimenter then handed the subject a sheet of paper listing the suggested topics--either positive or negative--and several blank sheets of paper. Examples of the positive episodes included "Got something you wanted," "Were given a compliment," "Came into money," and "Found out someone you liked you." Examples of the negative episodes included "You don't have enough money to buy something you want, i.e., food, outfit, car," "The last time you had a quarrel with someone important to you--parent, child, lover, spouse," " The last time you failed a test or did much poorer than you expected," "Got dumped by someone you were dating" (see Appendix E).

Video viewing. The videotape chosen for the positive mood induction was "Funniest Home Videos from America's Funniest Home Videos." This tape was based on a television show that was widely popular during the time this study was being conducted. The negative videotape was "Night and Fog," a 1955 documentary depicting Nazi war atrocities. "Night and Fog" had previously been used by Isen and Gorglione (1983) and Cunningham (1988). In both studies, self-report data revealed a significant increase in negative affect compared to pretest measures. Both videos were approximately the same length (34 and 35 minutes, respectively). After watching the videotapes, subjects were asked to rate the movies on four seven-point 
scales: good-bad, boring-interesting, amusing-not amusing, and entertaining-not entertaining (see Appendix E).

Dependent Variables

Blood pressure and heart rate readings, and saliva samples were collected following the experimental manipulation. In addition, self-report measures of mood were obtained immediately as (a) a check on the effectiveness of the manipulation, and (b) a means to later explore state affect as a mediator of relations between manipulations and immune function. Participants were asked to complete the Pennebaker Symptoms Emotion Checklist (SECL): A State Measure (Pennebaker, 1982). See Appendix F for a copy of the SECL. This scale's reliability is described in the Results section.

Subjects were then asked to fill out an Anonymous Evaluation of Research Assistants Form (Zillman \& Cantor, 1976). A copy of the form is found in Appendix G. A formal debriefing followed (a copy of the debriefing form is found in Appendix H).

\section{Saliva Assay}

Saliva samples were assayed for SIgA concentrations by Allercheck Laboratories, Portland, Maine, using the ImmunoQuest ${ }^{\mathrm{TM}}$ (Blake Biotechnologies, Harvard, Massachusetts) Enzyme Linked Immunosorbent Assay (ELISA) kit for measuring secretory and serum IgA concentrations. Briefly, the Immunoquest ${ }^{\mathrm{TM}}$ ELISA process calls for saliva samples to be prediluted and pipetted into wells which contain a protein (r-protein B) to which the IgA binds. Additionally, five serial 
dilutions of a reference sera were prepared and pipetted into individual wells. An HRP-conjugated goat anti-human IgA polyserum is then pipetted into each well. After a two-hour incubation period, the wells were decanted and washed several times with a wash buffer solution. An OPD (o-phenylenediamine dihydrochloride)/ Peroxide Buffer was added to the wells. The OPD/Peroxide Buffer turns the captured IgA molecules a color. The depth of color is determined by the concentration of IgA. After 20 minutes, $2 \mathrm{~N}$ sulfuric acid is padded to each well to stop the coloration process. The well plates are then read at $490 \mathrm{~nm}$ using a spectrophotometer. A best fit regression line was calculated in order to plot the unknown quantities of SIgA present in subject samples against the known quantities present in the serial dilutions of the reference sera. For the purpose of the present study, spectrophotometer readings were used as indicators of SIgA concentrations. Spectrophotometer readings (measured in absorption units) proved to be more sensitive indicators of SIgA concentrations. According to the best fit regression line any sample with a spectrophotometer reading below 117 absorption units contained zero $\mathrm{mg} / \mathrm{dl}$ of SIgA.

\section{Results}

\section{Preliminary Analyses}

SIgA data for two subjects, a male in the positive writing condition and a female in the negative writing condition, were lost in shipping to the lab. Their data were deleted from any SIgA analysis using pairwise deletion. Pairwise deletion leaves unequal n's in the cells, however, unequal n's is considered more preferable than the 
loss of power that would arise from deleting cases entirely (Cohen \& Cohen, 1979). Blood pressure scores from four subjects were out of range due to instrumentation/experimenter error. These values were re-coded as missing and pairwise deletion was used in all analyses involving blood pressure.

Group equivalence. Preliminary data analyses were conducted to determine if the experimental groups were equivalent. This was done to prevent the possibility that initial differences would confound the results of the study. All personality predictors to be used in moderator regression analyses, as well as baseline SIgA levels, blood pressure and heart rate were included in these analyses. The results of the $2 \times 2 \times 2$ analysis of variance (ANOVA), with induced mood (positive or negative), method (video vs. writing), and gender (male vs. female) as the three between groups factors, showed that between group differences did not exist for any of the variables with the exception of SIgA. There was a significant mood by method interaction, $\underline{F}(1,97)=4.33, \mathrm{p}<.05$, with subjects who had been assigned to the negative video condition having significantly lower SIgA levels than subjects in the negative writing condition $(\underline{M}=.34, \underline{S D}=1.68$ vs. $\underline{M}=.50, \underline{S D}=.28)$. This difference stemmed, in part, from the fact that one subject, a male in the negative writing condition, had SIgA levels 5 standard deviations above the mean. Inspection of this subject's data revealed that he had a cold. His data were, therefore, dropped from inclusion in any statistical analysis. Dropping this subject reduced the baseline SIgA differences to the .07 level, $\underline{F}(1,96)=3.35 .^{2}$ 
Gender. Preliminary analyses disclosed that gender interacted with mood induction to produce differences in mean arterial blood pressure, $\underline{F}(1,92)=5.21$, $p$ $<.05$. Since mean arterial pressure was the only dependent measure that produced these differences gender was retained as a variable only for analyses involving blood pressure.

Reliability Analyses. Cronbach's alpha coefficients obtained for moderator variable scales have been previously cited in the method section. All of the scales had moderate to good internal consistency reliability with the exception of the two subscales of the Introversion/Extroversion/Neuroticism scale (Eysenck, 1958). Because the Extroversion subscale had an alpha coefficient of only .37 , it was not used in any analysis. Although the neuroticism subscale, had marginal internal consistency reliability $(.70)$, it was used in moderator regression analysis.

\section{Manipulation Checks}

This study employed several measures to assess the effectiveness of the mood induction manipulations.

The first measure employed The Pennebaker Symptoms Emotion Checklist (Pennebaker, 1982). The scale was divided into two components: an affect component called "emotions", and a physical symptoms component called "symptoms". "Emotions" is a measure of negative affect and "symptoms" is a measure of physiological state. An initial reliability analysis of the emotions scale disclosed an alpha coefficient of $.65,{ }^{3}$ however, an item-total analysis showed that if one of the 
items, "anxious" was eliminated from the total scale score, the resulting alpha would be .78. A follow-up factor analysis procedure confirmed these results.

Two variables, the single item "anxious" and a composite variable "negative emotions" comprised of the remaining four emotions items (angry, guilty, sad \& unhappy) were entered into a multivariate analysis of variance (MANOVA) with induced mood condition as the between groups variable. The results of the MANOVA showed a marginal effect for induced mood, but only for the negative emotions factor, $\underline{F}(1,102)=3.26, \underline{p}<.07 .^{4}$ Subjects in the negative mood condition reported higher levels of negative emotions than subjects in the positive condition ( $\underline{M}$ $=2.42, \underline{\mathrm{SD}}=1.43$ vs. $\underline{\mathrm{M}}=2.01, \underline{\mathrm{SD}}=1.12$ ).

A 2 (mood induction) by 2 (method of induction) MANOVA was run to determine whether mood interacted with method. The overall MANOVA was significant, $\underline{\mathrm{F}}(2,99)=3.05, \mathrm{p}<.05$. Univariate analyses revealed that negative emotions was statistically significant, $\underline{F}(1,100)=6.16, \underline{p}=.01$ whereas, anxious was not, $\underline{F}(1,100)=.03, \underline{p}=$ n.s.). A post hoc Least Significant Difference (LSD) test showed that subjects in the negative video condition reported significantly higher levels of negative affect than subjects in any of the other groups $(\mathrm{p}<.05)$. The mean number of negative emotions and physical symptoms that were reported by condition are shown in Figure 1.

The "symptoms" component, measuring physiological distress had an alpha coefficient of .75 . This alpha level is consistent with that reported by Pennebaker (1982). Furthermore, Pennebaker stated that attempts to discern meaningful 
subfactors using factor analysis have not been successful. Therefore, the symptoms checklist total score was used..$^{5}$ A oneway analysis of variance showed no significant differences in symptoms by mood condition. A $2 \times 2$ ANOVA was performed to see if method masked the effects of mood. There were no interaction effects; however, there was a significant main effect for method, $\underline{\mathrm{F}}(1,100)=5.21, \mathrm{p}<.05)$. Subjects in the movie condition reported higher levels of physical symptoms $(\underline{M}=1.86, \underline{S D}$ $=.85)$ than subjects in the writing condition $(\underline{\mathrm{M}}=1.54, \underline{\mathrm{SD}}=.56)$.

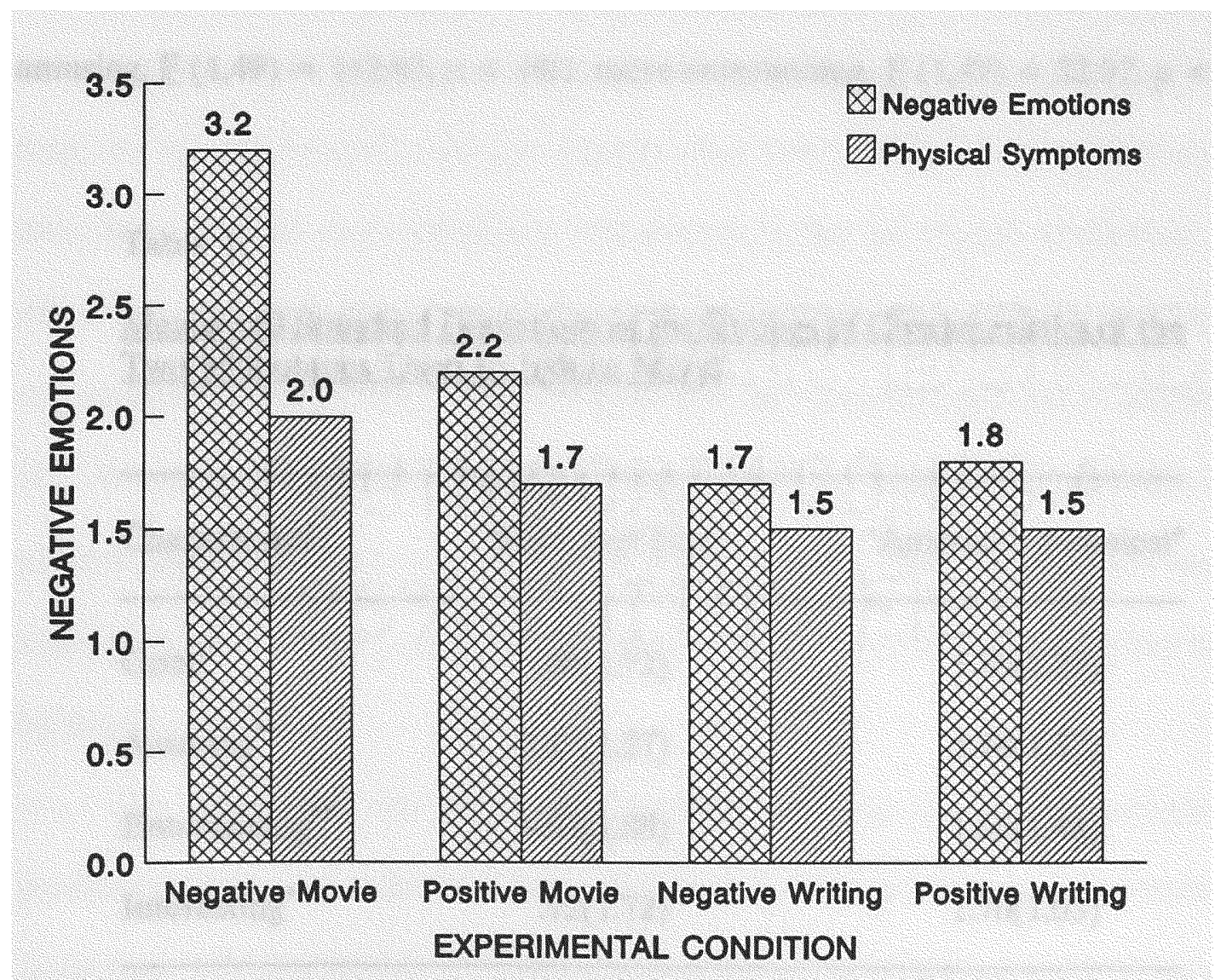

Figure 1. The Mean Number of Self-Reported Negative Emotions and Physical Symptoms by Valence of Induced Mood and Method of Induction 
To summarize, the mood manipulation produced marginal differences in selfreport of emotions, but method of induction interacted with mood induction to produce the highest level of self-report negative emotions in the negative movie condition. Physical symptoms were not affected by mood induction, but higher levels of symptoms were reported in the video condition.

Rating of videos. Another component of the manipulation check concerned subjects reactions to the videos they viewed. A Hotelling's $\mathrm{T}^{2}$ revealed subjects experiences of the two videos differed significantly, $\underline{\mathrm{F}}(4,46)=18.99, \mathrm{p}<$ .001. Subjects rated the positive video as better, $\underline{F}(1,49)=3.95, p=.05$, more amusing, $\underline{F}(1,49)=112.63, p<.001$, more entertaining, $\underline{F}(1,49)=22.97, p<.001$,

\section{Table 1.}

Means and Standard Deviations of the Ratings of Characteristics of the Two Videotapes Used to Induce Mood

\begin{tabular}{lcc} 
Characteristic & "Night and Fog" & "America's Funniest" \\
\hline Good $^{*}$ & $.88(1.72)$ & $1.70(1.23)$ \\
Amusing $^{* *}$ & $-2.17(1.27)$ & $1.78(1.37)$ \\
Entertaining $^{* *}$ & $-.67(1.88)$ & $1.56(1.48)$ \\
Interesting $^{*}$ & $.92(1.72)$ & $1.70(1.03)$
\end{tabular}

${ }^{*} \mathrm{p} \leq .05,{ }^{* *} \mathrm{p} \leq .001$ 
and more interesting, $\underline{F}(1,49)=4.04, \underline{p}=.05$. Means and standard deviations of video ratings are listed in Table 1 . Of the 24 subjects viewing the negative video, 3 had seen it before. Of the 27 subjects viewing the positive video, 3 had seen it before.

Rating of stories. A further assessment of the effectiveness of the manipulation was conducted on the stories subjects in the writing condition wrote. Two independent raters conducted blind evaluations of the stories for the degree of positiveness and negativeness. The average interrater reliability rating was $\underline{r}=.90$ on a six-point scale from -3 (very negative) to +3 (very positive). Fifty-three subjects wrote 1 story; 37 subjects wrote two stories; and 22 subjects wrote 3 stories. Ratings from the two raters were averaged together and three ANOVAS were conducted to determine if there were significant differences in the two mood conditions. The affect content differed significantly for each of the three stories subjects wrote in the expected direction, $\underline{\mathrm{F}}(1,51)=596.17, \underline{\mathrm{p}}<.001$ for story one, $\underline{\mathrm{F}}(1,35)=240.16, \underline{\mathrm{p}}<$ .001 for story 2 , and $\underline{F}(1,20)=524.68, \mathrm{p}<.001$ for story three. Stories in the positive mood condition were significantly more positive than stories in the negative mood condition. Table 2 presents the means and standard deviations of story ratings by mood condition.

To summarize, the mood manipulation was only moderately successful in producing changes in affective state. Induced mood was tempered by method of induction. The interaction of valence of mood induction with method of induction produced the highest levels of self-report negative affect in the negative movie 
Table 2.

Means and Standard Deviations of Ratings of Negative and Positive Stories Written to Induce Mood

\begin{tabular}{llll}
\hline & $\mathrm{n}$ & Negative & Positive \\
\hline Story $1^{* *}$ & 53 & $-1.58(0.63)$ & $2.43(0.51)$ \\
Story $2^{* *}$ & 37 & $-1.56(1.04)$ & $2.42(0.48)$ \\
Story $3^{* *}$ & 22 & $-1.94(0.46)$ & $2.38(0.42)$ \\
\hline
\end{tabular}

Note. A rating of zero indicated that the story was neither negative or positive; ${ }^{*} \mathrm{p} \leq .05$. ${ }^{* *} \mathrm{p} \leq .001$

condition. Within the method of induction conditions, subjects wrote more positive stories in the positive condition than in the negative condition. Also subjects viewed the videos to be less amusing and entertaining in the negative condition.

\section{Experimental Findings}

The principal hypothesis of this study involved an interaction between time of treatment (baseline vs. posttest) and valence of mood induction (positive vs. negative). It was hypothesized that negative mood induction would lower SIgA levels from pretest to posttest across method conditions, and that positive mood induction would raise SIgA from pretest to posttest across method conditions (H1). A split-plot multivariate analysis of covariance (MANCOVA) with valence of mood induction 
(positive vs. negative) and method of induction (video viewing vs. essay writing) as the between group variables and time (baseline vs. posttest) as the within group variable was used to test this hypothesis. Baseline and posttreatment flow rates were used as covariates. The results did not support the hypothesis. Figure 2 depicts the change curve of SIgA levels from baseline to posttest by mood and method conditions. Mood induction condition (positive vs. negative) did not change SIgA levels over time, $\underline{\mathrm{F}}(1,92)=1.83$, $\underline{\mathrm{ns}}$, nor was there an interaction of mood and method, $\underline{F}(1,92)=.15$, $\underline{\text { ns. }}$.

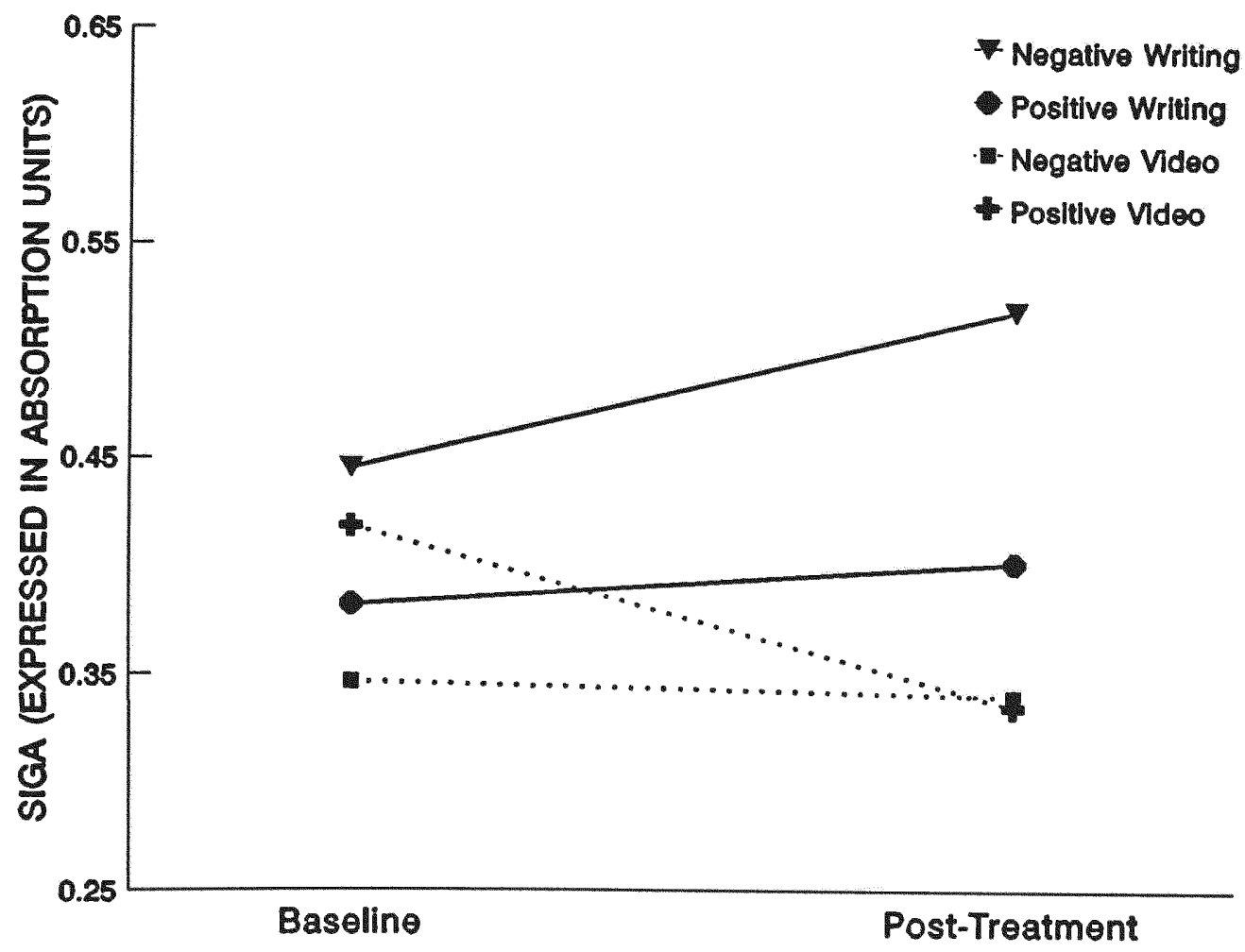

TIME OF SIGA MEASUREMENT

Figure 2. Changes in Concentration of Secretory Immunoglobulin A After Inducing Positive or Negative Mood Using Two Methods of Induction: Watching a Videotape or Writing an Essay 
Blood Pressure and Heart Rate. It also was hypothesized that negative mood would raise blood pressure and heart rate across method of induction conditions (H2). All analyses involving blood pressure utilized mean arterial pressure (MAP) which weights diastolic pressure more heavily than systolic (Guyton, 1966). The formula for MAP is:

$$
\mathrm{MAP}=\mathrm{D}+1 / 3(\mathrm{D}-\mathrm{S})
$$

where $\mathrm{D}$ refers to diastolic and $\mathrm{S}$ refers to systolic blood pressure.

Two separate split-plot MANOVAs were used to test this hypothesis. The MANOVA for blood pressure included gender as a between subjects factor as well as mood and method, and as with the other analyses time of measurement was a within subjects factor. The MANOVA for heart rate was the same, except that gender was not included as a variable. The results of these analyses yielded an overall gender by mood by time interaction, $\underline{F}(1,92)=5.21, \underline{p}<.05$ for blood pressure. There were no significant differences in heart rate from baseline to postmanipulation. Figure 3 depicts the results for blood pressure. As can be seen, the hypothesis for blood pressure was not supported. However, females in the positive mood induction condition experienced a significant increase in blood pressure from baseline to posttest, $\underline{\mathrm{t}}(27)=-3.60, \underline{\mathrm{p}}<.01$.

To summarize the experimental findings, SIgA concentrations were not significantly altered by negative or positive mood induction. Heart rate, too, was not affected by valence of mood induction. Gender interacted with mood induction to produce changes from baseline to posttest in mean arterial pressure. The hypothesis 


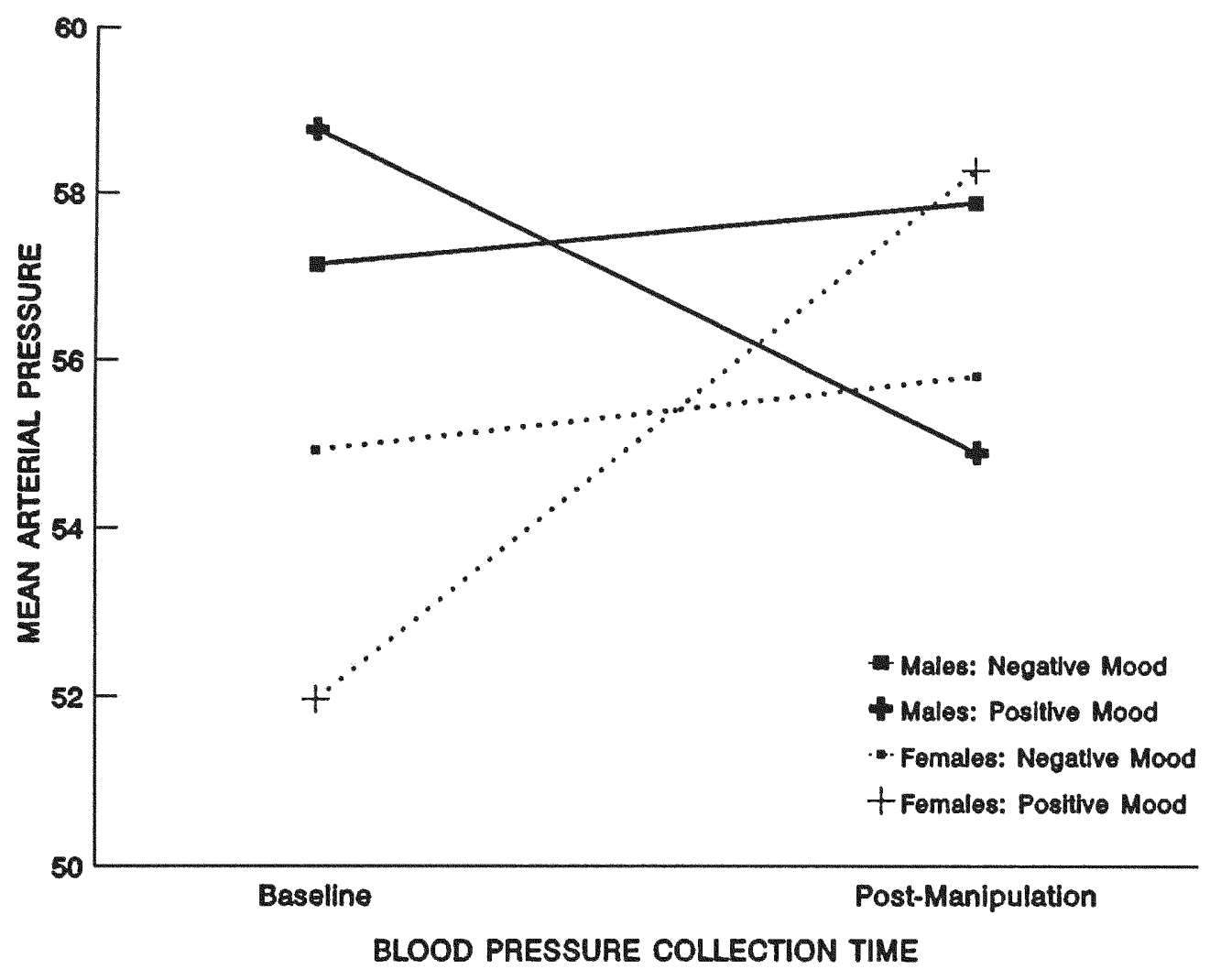

Figure 3. The Effect of Positive and Negative Mood Induction on Blood Pressure for a Sample of Male and Female College Students

that negative mood induction would increase blood pressure and positive mood induction would decrease blood pressure was not supported. The third hypothesis (H3) that focus of mood induction would not affect outcomes of physiological measures is moot in as much as the principal hypothesis that mood induction would affect SIgA was not affirmed, however; there were no significant effects of method of mood induction on SIgA, blood pressure, or heart rate. 
Moderator Regression Variables

Moderator regression analyses were conducted to address hypotheses $\mathrm{H} 4$ to $\mathrm{H} 7$ concerning the interactive effects of personality variables with the mood induction manipulation. The first step of these analyses was to determine which personality variables were predictors of SIgA and in turn, which variables interacted with the mood manipulation. This was done using a "pool" subcommand in the MANOVA routine in SPSS/PC+ which allows one to discern interaction effects between a

Table 3.

Results of Moderator Regressions Used to Test for Interactions Between Personality Traits and Valence of Mood Induction as Predictors of Secretory Immunoglobulin A Concentration

Trait

Depression

Neuroticism

$\underline{F}(1,90)=5.80^{*}$

$\underline{F}(1,90)=6.49^{* *}$

$\underline{F}(1,91)=1.02$

$\underline{F}(1,93)=0.13$

$\underline{F}(1,91)=0.10$

$\underline{F}(1,91)=8.09^{* *}$

$\underline{F}(1,91)=0.51$

Mood X Trait

$\underline{E}(1,91)=4.55^{*}$

$\underline{F}(1,93)=0.86$

Rumination

Positive Afffect

Negative Affect

${ }^{*} \mathrm{p} \leq .05,{ }^{* *} \mathrm{p} \leq .01$ 
continuous variable (in this case personality variables) and a categorical variable. The results of these first analyses are summarized in Table 3. As can be seen, positive affect and depression were significant predictors of SIgA, and formed interaction terms. Neuroticism, while not a significant predictor by itself, formed an interaction term with mood.

The second phase of the moderator variable analyses was to determine where the effects lay using procedures outlined by Aiken and West (1992). Simple slopes for the regressions that contained a significant interaction term were computed, tested, and plotted. The continuous personality variables were "centered" by subtracting the mean. This placed the mean of the variable at 0 . Dummy codes of 1 and 0 were employed to represent high and low levels of the two categorical factors. To predict SIgA, mood (dummy-coded), the centered affect variable, the interaction term, and the covariates (baseline SIgA and postmanipulation flow rate) were entered into a regression equation. Finally, two other regressions were conducted calculating high and low levels of the moderator variables by adding one standard deviation above the mean to make "high" and subtracting one standard deviation below the mean to make "low". The results of all three of these regressions were then plotted to determine the direction of the interaction. The variables depression, positive affect, and neuroticism had the same pattern of interaction with mood.

Highly depressed people, highly neurotic people and people low in positive affect (i.e, sad or lethargic people) had higher SIgA levels in the negative mood 
condition. The post hoc tests of the simple slopes revealed that for depression the relation between laboratory induced mood and SigA concentration was not significant for those whose self-rated depression was lower than the mean for the group, $\underline{t}=-$ $.57, \underline{\mathrm{ns}}$, it was marginal for those whose self-rated depression was average, $\underline{\mathrm{t}}=1.73$, $\mathrm{p} \leq .10$, and it was significant for those whose self-rated depression was higher than the group mean, $\underline{\mathrm{t}}=3.02, \mathrm{p} \leq .01$. The patterns were similar for neuroticism and positive affect. There was no relation between induced mood and SIgA concentration for those who scored high on trait positive affect, $\underline{\mathrm{t}}=.27$, $\underline{\mathrm{ns}}$, or those who scored at the mean, $\underline{\mathrm{t}}=1.67, \underline{\mathrm{ns}}$, but was significant for those who had scored below the mean on the trait, $\underline{\mathrm{t}}=2.57, \mathrm{p} \leq .01$. For neuroticism, there was no relation between induced mood and SIgA concentration for those who scored low, $\underline{\mathrm{t}}=-.279, \underline{\mathrm{ns}}$, a marginal relation for those who scored at the mean, $\underline{\mathrm{t}}=1.80, \underline{\mathrm{p}} \leq .10$, and a significant relation for those who had scored high, $\underline{\mathrm{t}}=2.22, \mathrm{p} \leq .01$. In addition, the moderating effects of these mood-negative characteristics occurred in negative mood induction conditions and did not effect the positive mood induction conditions.

Figure 4 depicts the interactions of depression, neuroticism, low positive affect with mood induction. Contrary to expectations, positive affect did not yield any buffering effects of mood induction on SIgA and negative affect did not interact with mood induction to lower SIgA. However, depression, low positive affect (defined as lethargy), and neuroticism (or excess emotionality) buffered the effects of negative mood induction to raise SIgA levels. 

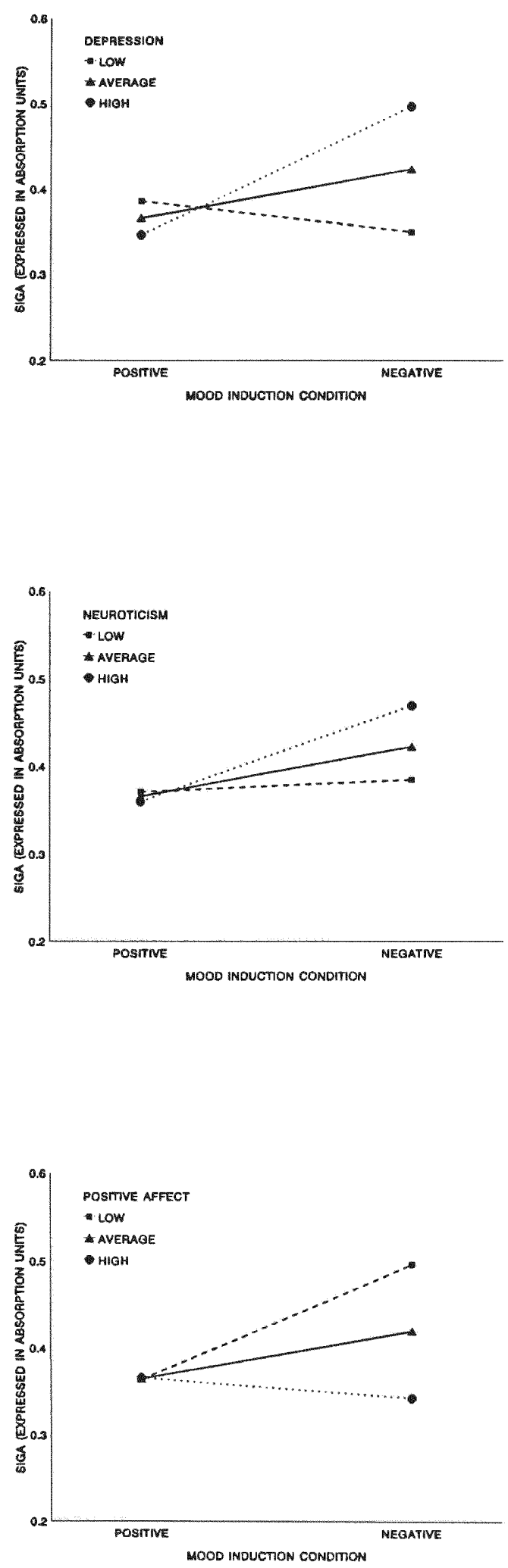

Figure 4. Plots of Simple Slopes for Moderator Regression Interactions 
Table 4.

Standard Deviations and Regression Coefficients Used to Plot the Significant Interactions in the Moderator Regression Analyses

Standard Deviation

Regression Coefficient

Depression

13.46

.0055

Induced Mood

$-.0567$

Interaction

$-.0070$

(Intercept)

.4229

Neuroticism

3.62

.0117

Induced Mood

$-.0618$

Interaction

$-.0131$

(Intercept)

.4277

Positive Affect

6.25

$-.0122$

Induced Mood

$-.0545$

Interaction

.0124

(Intercept)

.4199

Note. The dependent variable for these analyses was the concentration of secretory immunoglobulin $\mathrm{A}(\mathrm{SIgA})$ as expressed in nanometers. 
Table 4 presents the regression coefficients and standard deviations used to plot the moderator regressions.

\section{Mediational Analyses}

Self-report of emotions and symptoms were entered into two separate analysis of covariance to determine if they mediated the results between mood induction and outcome measures. Neither self-report of emotions nor self-report of symptoms emerged as mediators.

Items on the health-survey index were also tested for their mediational effects either using analyses of covariance or hierarchical regression depending on whether the variable was continuous or categorical. Of all the variables on the health inventory, only taking prescription drugs and being a "day person" predicted SIgA, but neither variable mediated the effects of mood.

Subsidiary Analysis

The Anonymous Evaluation of Assistants form was used as the final manipulation check. It was hypothesized that subjects in the negative mood induction condition would evaluate the performance of the assistants more poorly than subjects in the positive mood induction. A total scale score was computed for the 5 items on the Anonymous Evaluation Form. The reliability of the total scale was .95 . Although the means obtained in an ANOVA by mood induction condition were lower in the negative than the positive mood induction $(\underline{M}=13.92$ vs. $\underline{M} 14.40)$ these differences were not statistically significant. Contrary to the hypothesis, subjects evaluations of the assistants were not affected by the mood induction manipulation. Further 
analyses were conducted to determine whether method of induction or gender played a part in the evaluations. There was a significant effect for gender, $\underline{F}(1,100)=4.71$, $\mathrm{p}<.05$. Women across all conditions evaluated the experiment and experimenters more negatively than men $(\underline{\mathrm{M}}=14.69, \underline{\mathrm{SD}}=3.26$ vs. $\underline{\mathrm{M}}=13.66, \underline{\mathrm{SD}}=1.00)$. Method of induction did not significantly alter the evaluations.

\section{Discussion}

The present study tested the effects of laboratory induced mood on SIgA using two different mood induction techniques. In doing so, care was taken to control for extraneous factors including salivary flow rate and behavioral characteristics such as alcohol consumption, and cigarette smoking that may have influenced results. The principal hypothesis of the study was not supported. Laboratory induced positive mood did not raise SIgA levels, and laboratory induced negative mood did not lower SIgA levels. These results contradict ones obtained in previous SIgA studies using videos to induce positive or negative mood (Dillon et al., 1986; Vela, 1990). It should be noted that neither the Dillon et al. nor Vela controlled for salivary flow rate in their analysis of SIgA concentrations. Furthermore, both studies ran subjects in groups. The effect of watching videos in groups may be similar to social facilitation in that presence of others enhances the dominant response; in this case enjoyment (Chapman \& Wright, 1976; Fuller \& Sheehy-Skeffington, 1974). It is also possible that the presence of others raises feelings of affiliation which in turn enhance immunity (Jemmott et al., 1983; McClelland et al., 1985; McClelland, et al., 1980; McClelland \& Krishnit, 1988). 
Outcome differences in the present study could be due to the type of video used. It may be that the Richard Pryor video used by Dillon et al. (1985) and the Robin Williams used by Vela et al. (1990) were considered funnier than the "Best of American Home Video" used in the present study. It is suggested that future studies use replicates of stimulus material.

It is also possible that the negative video in the present study was not strong enough to elicit the kinds of affectively linked emotional changes seen in other research (Zakowski et al., 1992). Research by Isen and Gorglione (1983) and Cunningham (1988) using the same video, "Night and Fog" (documenting Nazi war atrocities) found the same changes in negative affect using self-report data as did the present study. However, in the present study, self-reported negative feelings were not associated with immunosuppression. A study by Zakowski et al. (1992) employed a video depicting explicit surgical procedures to induce negative affect. They found that subjects who watched the video had marked decreases in lymphocyte proliferation after a 15-minute viewing period. It could be the case that a videotape manipulation has to be explicitly gory to produce a corresponding drop in immunity in student subjects, or that Nazi war atrocities have received so much publicity in recent years, that subjects have become desensitized.

It may be argued that studies that seek to alter immunity via mood induction do not produce definitive changes consistent with the direction of the emotion (i.e., positive mood equals immunoenhancement and negative mood equals immunosuppression); they might instead produce a greater variability in responses. 
For example, Futterman, Kemeny, Shapiro, Polonsky and Fahey (1992) investigated the effects of induced mood on immunity by having trained actors act out roles characterized by the emotions of, happiness, fear, and depression, or neutral. They found that affective state had no effect on any of the immunity measures they used (T cell, T4 cell, NK cell, large granular lymphocytes, etc.), Instead there was significantly more variability in the measures (amount of change up or down) following the portrayal of the emotional state compared to an affectively neutral control state. To take another example Landmann, Muller, Perinin, Wesp, Erne, and Buhler (1984) exposed subjects to either physical stress in the form of bike riding, or psychological stress induced by the Stroop test. This produced an increase in total numbers of monocytes, B and NK cells. Landmann et al.'s results run contrary to studies that show laboratory induced stressors drive immune systems parameters down. Similarly, Knapp et al. (1992) found that recollection of both negative and positive experiences caused a decrease in $\mathrm{T}$ cell mitogen response. Even studies that find evidence for laboratory induced stress having detrimental effects on immunity, do not find that these results are consistent across all immune parameters. For example, Zakowski et al. (1992) found marked decreases in lymphocyte proliferation in subjects exposed to a stressful movie, but only for one indicator, and only at one concentration level for the mitogen used to measure immune functioning. Hypotheses Concerning Blood Pressure and Heart Rate

This second hypothesis of this study was not supported: Negative mood induction did not raise blood pressure or heart rate. For women, however, blood 
pressure increased greatly in the positive mood induction condition from baseline to posttest. Men, on the other hand, did not experience any significant changes in blood pressure.

\section{The Role of Stable Personality Traits and Immunology}

It was hypothesized that high positive affect and optimism would enhance physiological outcomes in the positive affect condition and buffer against the effects in the negative affect condition ( $\mathrm{H} 4$ and $\mathrm{H} 5$ ). It was also hypothesized that depression, rumination, and neuroticism would interact with mood to produce lower SIgA levels and higher blood pressure and heart rate in both the positive and negative mood conditions (H6 and H7). These hypotheses were not supported. Instead, depression, low positive affect (defined as sadness and lethargy), and neuroticism interacted with negative mood to raise SIgA levels.

Few studies have examined the interaction of personality variables and stressors and immunity. An exception is Kubitz et al. (1986) who found that healthlocus of control was inversely related to SIgA concentrations. Taylor and Brown (1986) note that depressives are more realistic in their appraisal of the world in that they realistically assess the degree of control they have over the world. In the present study, depressives, when in a stress situation, had higher SIgA levels.

Denney and Froehlich (1992) had subjects who scored either high or low on the Beck Depression Inventory under a mood induction manipulation using a sad movie or a neutral movie for a period of four weeks. The highly depressed subjects in the sad film condition had a significant decline in the number of T-8 suppressor 
cells after a four-week period. As with the current study, the Denney and Froelich (1992) study found that stable personality traits interact with situational variables to affect the immune system.

The role of stable personality traits interacting with situational variables to affect SIgA was shown in work by McClelland and his colleagues concerning the moderating effects of "inhibited power motivation syndrome" (McClelland \& Krishnit, 1988, Jemmott et al., 1983; Jemmott et al., 1989). According to McClelland (1980) men who exhibit the "inhibited power motive" are similar to type A men, but they keep their anger expression controlled. It is possible that this kind of control is similar to the health locus of control issue discussed earlier, such that people who believe they have a high degree of control may suffer from immunosuppression during times of stress. This interpretation is consistent with the fact that depression is related to increased immunity during times of stress. As previously noted, depressives do not believe they exert a great deal of control over situations.

Another stable personality characteristic that has been found to interact with situational factors to affect SIgA is humor. Martin and Dobbin (1988) found that trait humor predicted SIgA when interacting with situational stress. Similar results were found in the present study in that a trait variable interacts with a situational variable to predict SIgA.

Depression and immunity

The link between depression and immunity has been studied extensively. Herbert and Cohen (1993a) conducted a meta-analysis on 35 studies designed to test 
the relation between depression and immunity. Included in their analysis were studies that examined the effects of both clinical depression and depressed mood on immunity. Herbert and Cohen's findings indicate that depression is related to suppressed immune functioning as measured by decreased mitogen proliferation responses, decreased numbers of NK cells, decreased levels of $\mathrm{B}$, and $\mathrm{T}$ cells. Most of the studies achieved a moderate effect size. However, their meta-analysis did not include studies that looked at an interaction between clinical depression or depressed mood and state negative affect. It could be the case that situational negative affect arouses immunity in depressives.

In a 1992 literature review on depression and immunity, Weisse included studies involving clinical depression and depression following separation in humans and in animals. The results of the studies in her review differed from those in the Herbert and Cohen meta-analysis (1993a). Her overall findings suggest that lowered immunocompetence is more likely to be found in clinically depressed people than in people with situationally linked depression. The Weisse review, similar to the Herbert and Cohen meta-analysis did not include experimental studies involving mood manipulation.

Neuroticism and health

Neuroticism and general defensiveness, as well as internal locus of control were inversely correlated with several serum immunoglobulins in a 1984 study by Ursin and colleagues on a sample of female school teachers. Larsen and Kasimatis (1991) found that neuroticism correlated with Type A behavior and hostility and 
predicted gastrointestinal distress, but did not predict upper respiratory infections. The results of the present study suggest that neuroticism would not predict onset of upper respiratory infection since neurotics would have increased SIgA to buffer the effects of stress.

\section{Chronic versus Situational Stressors and SIgA}

There is some reason to believe that SIgA fluctuations are more related to the presence of chronic stressors (i.e., stressors lasting anywhere from 2-3 days to several months). Many of the studies previously reviewed used exam stress as an independent measure. The stress symptoms students experience before an exam may asymptote on the day of the exam, but may actually begin their rise (or fall) several days before.

With regard to chronic stress and SIgA, Byun, J. and Lieberman, L. S. (1993: Personal Communication) reported that Korean victims of the 1992 Los Angeles riots had lower levels of SIgA and higher levels of salivary cortisol compared to a control group. The magnitude of the correlations were directly related to the extent of life changes caused by the riots. Byun and Lieberman collected their samples during a three to six month period following the riots. ${ }^{6}$

\section{Conclusions}

By including trait personality moderator regression analysis and controlling for the presence of extraneous variables associated with distorted findings such as the presence of existing infections, alcohol consumption or cigarette smoking behaviors amongst their subjects, the present study makes a notable contribution to the 
psychoneuroimmunology literature. Furthermore, although SIgA may not be responsive to short-duration fluctuations in mood caused by laboratory manipulations, there is evidence that stable personality traits interact with mood to affect concentration levels. Further research is needed to determine whether these fluctuations have clinical significance. 


\section{References}

Ader, R., \& Cohen, N. (1975). Behaviorally conditioned immunosuppression. Psychosomatic Medicine, 37, 333-340.

Ader, R., \& Cohen, N. (1981). Conditioned immunopharmacologic responses. In R. Ader (Ed.) Psychoneuroimmunology (pp. 281-319). New York: Academic Press.

Aiken, L. S., \& West, S. G. (1991). Multiple regression: Testing and interpreting interactions. Newbury Park, CA: Sage Publishing.

Aufricht, C., Tenner, H. R., Khoss, A. E., Wurst, E., \& Herkner, K. (1992). Salivary IgA concentrations is influenced by the saliva collection method. European Journal of Clinical Chemistry and Clinical Biochemistry, 30(2), 81-83.

Bates, J. F., \& Adams, D. (1968). The influence of mental stress on the flow of saliva in men. Archives of Oral Biology, 13, 593-596.

Brandtzaeg, P. (1971). Human secretory immunoglobulins--VII: Concentrations of parotid $\operatorname{IgA}$ and other secretory proteins in relation to the rate of flow and duration of secretory stimulus. Archives of Oral Biology, 16, 1295-1310.

Brannon, L., \& Feist, J. (1992). Health Psychology. Belmont, CA: Wadsworth Publishing Co.

Camara, E. G., \& Danao, T. C. (1989). The brain and the immune system: A psychosomatic network. Psychosomatics, $\underline{30}, 140-146$.

Caprara, G. V. (1986). Indicators of aggression: The dissipation-rumination scale. Personality and Individual Differences, 7, 763-769.

Chaikin, A. L., Derlaga, V. J., \& Miller, S. J. (1976). Effects of room environment on 
self-disclosure in a counseling analogue. Journal of Counseling Psychology, 5, 479481.

Chapman, A., \& Wright, D. S. (1976). Social enhancement of laughter: An experimental analysis of some companion variables. Journal of Experimental Child Psychology, 21, 201-218.

Cohen, J., \& Cohen, P. (1983). Applied multiple regression/correlation analysis for the behavioral sciences (2nd ed.). Hillsdale, NJ: Lawrence Erlbaum Associates. Cohen, S., Tyrrell, D. A. J., \& Smith, A. P. (1991). Psychological stress and susceptibility to the common cold. The New England Journal of Medicine, $\underline{325}$, 606-636.

Cook T. D., \& Campbell, D. T. (1979). Quasi-experimentation: Design and analysis issues for field settings. Boston: Houghton Mifflin.

Cunningham, M. R. (1988). Does happiness mean friendliness? Personality and Social Psychology Bulletin, 14, 283-297.

Daruna, J. H., \& Morgan, J. E. (1990). Psychosocial effects on immune function: Neuroendocrine pathways. Psychosomatics, $31,4-12$.

Denney, D. R., \& Froehlich, P. J. (1992, August). Mood induction and leukocyte subclasses: An experimental study. Paper presented at the meeting of the American Psychological Association, .

Dillon, K. M., Minchoff, B., \& Baker, K. (1985). Positive emotional states and enhancement of the immune system. International Journal of Psychiatry in Medicine, 15, 13-17. 
Dimsdale, J. E., Young, D., Moore, R., \& Strauss, H. W. (1987). Do plasma norepinephrine levels reflect behavioral stress? Psychosomatic Medicine, $\underline{49}, 375$ 38

Dubitsky, S., Weber, R., \& Rotton, J. (1993, June). Collection of saliva samples for biochemical assay: A comparison of methods. Presented at the American Psychological Society Conference, Chicago, IL.

Eysenck, H. J. (1958). A short questionnaire for the measurement of two dimensions of personality. Journal of Applied Psychology, 42, 14-17.

Frijon, J. Y., \& Laurencelle, L. (1993). Analysis of covariance: A proposed algorithm. Educational and Psychological Measurement, 53, 1-18.

Fuller, G. C., \& Sheehy-Skeffington, A. (1974). Effects of group laughter on response to humorous material, a replication and extension. Psychological Reports, $\underline{35}$, 531-534.

Futterman, A. D., Kemeny, M. E., Shapiro, D., Polonsky, W., \& Fahey, J. L. (1992). Immunological variability associated with experimentally-induced positive and negative affective states. Psychological Medicine, 22, 231-238.

Geiser, D. S. (1989). Psychosocial influences on human immunity. Clinical Psychology Review, 9, 689-715.

Green, M. L., Green, R. G., \& Santoro, W. (1988). Daily relaxation modifies serum and salivary immunoglobulins and psychophysiologic symptom severity. Biofeedback and Self-Regulation, 13, 187-199.

Green, R. G., \& Green, M. L. (1987). Relaxation increases salivary immunoglobulin 
A. Psychological Reports, 61, 623-629.

Greenberg, S. S. (1989). Immunity and survival. New York: Plenum Publishing.

Guyton, A. C. (1966). Textbook in medical physiology. Philadelphia: Saunders.

Herbert, T. B., \& Cohen, S. (1993a). Depression an Immunity: A meta-analytic review. Psychological Bulletin, 113, 472-486.

Herbert, T. B. \& Cohen, S., (1993b). Stress and immunity in humans: A meta-analytic review. Psychosomatic Medicine, 55, 364-379.

Isen, A. M., \& Daubman, K. A. (1984). The influence of affect on categorization. Journal of Personality and Social Psychology, 47, 1206-1217.

Isen, A. M., \& Gorglione, J. M. (1983). Some specific effects of four affect-induction procedures. Personality and Social Psychology Bulletin, 9, 136-143.

Jemmott III, J. B., \& McClelland, D. C. (1989). Secretory IgA as a measure of resistance to infectious disease: Comments on Stone, Cox, Valdimarsdottir, and Neale. Behavioral Medicine, 15 , 63-71.

Jemmott III, J. B., Borysenko, M., Chapman, R., Borysenko, J. Z., McClelland, D. C., Meyer, D., \& Benson, H. (1983). Academic stress, power motivation, and decrease in secretion rate of salivary secretory immunoglobulin A. The Lancet, 1, 1400-1402.

Jemmott, J. B., \& Locke, S. E. (1984). Psychosocial factors, immunologic mediation, and human susceptibility to infectious diseases: How much do we know? Psychological Bulletin, 95, 78-108.

Jemmott, J. B., \& Magliore, K., (1988). Academic stress, social support, and secretory 
immunoglobulin A. Journal of Personality and Social Psychology, 55, 803-810.

Jemmott, J. B., Hellman, C., McClelland, D. C., Locke, S. E., Kraus, L. Williams, R. M., \& Valeri, C. R. (1990). Motivational syndromes associated with natural killer cell activity. Journal of Behavioral Medicine, 13 , 53-73.

Kallestad Laboratories, Inc. (1984). Technical Bulletin. Austin, TX: author.

Kemeny, M. E., Solomon, G. F., Morley, J. E., \& Herbert (1992).

Psychoneuroimmunology. In C. B. Nemeroff (Ed.) Neuroendocrinology (pp. 563591). Boca Raton, FL: CRC Press.

Kerr, A. C. (1961). The psychological regulation of salivary secretions in man. In R.

C. Greulish, J. B. Macdonald, \& M. A. Rushton (Eds.) International serious of monographs in oral biology, Vol I. Oxford: Pergamon Press.

Kiecolt-Glaser, J. K., \& Glaser, R. (1988). Methodological issues in behavioral immunology research with humans. Behavior and Immunity, 2 , 67-78.

Kiecolt-Glaser, J. K., \& Glaser, R. (1989). Psychoneuroimmunology: Past, present, and future. Health Psychology, 8, 677-682.

Kiecolt-Glaser, J. K., Garner, W., Speicher, C., Penn, G., Holliday, J., \& Glaser, R. (1984). Psychosocial modifiers of immunocompetence in medical students. Psychosomatic Medicine, 46, 7-13.

Kirk, R. E. (1982). Experimental design: procedures for the behavioral sciences. Pacific Grove, CA: Brooks/Cole Publishing.

Knapp, P. H., Levy, E. M., Giorgi, R. G., Black, P. H., Fox, B. H., \& Heeren, T. C. (1992). Short-term immunological effects of induced emotion. Psychosomatic 
$\underline{\text { Medicine, }}$ 54, 133-148.

Kubitz, K. A., Peavey, B. S., \& Moore, B. S. (1986). The effect of daily hassles on humoral immunity: An interaction moderated by locus of control. Biofeedback and Self-Regulation, 11, 115-123.

Landmann, R. M. A., Muller, F. B., Perini, C., Wesp, M., Erne, P., \& Buhler, F. R., (1984). Changes in immunoregulatory cells induced by psychological and physical stress: Relationship to plasma catecholamines. Clinical Experimental Immunology, 58, 127-135.

Larsen, R. J., \& Kasimatis, M. (1991). Day-to-day physical symptoms: Individual differences in the occurrence, duration, and emotional concomitants of minor daily illnesses. Journal of Personality, 59, 387-423.

Martin R. A., \& Dobbin, J. P. (1988). Sense of humor, hassles, and immunoglobulin A: Evidence for a stress-moderating effect of humor. International Journal of Psychiatry in Medicine, 18, 93-105.

McClelland, D. C., Alexander, C., \& Marks, E. (1982). The need for power, stress, immune function, and illness among male prisoners. Journal of Abnormal Psychology, 91, 61-70.

McClelland, D. C., Floor, E., Davidson, R. J., \& Saron, C. (1980). Stressed power motivation, sympathetic activation, immune function, and illness. Journal of Human Stress, $\underline{6}, 11-19$.

McClelland, D. C., \& Krishnit, C. (1988). The effect of motivational arousal through films on salivary immunoglobulin A. Psychology and Health, $2,31-52$. 
McClelland, D. C., Ross, G., \& Patel, V. (1985). The effect of an academic examination on salivary norepinephrine and immunoglobulin levels. Journal of Human Stress, 11, 52-59.

Mouton, C., Fillion, L., Tawadros, E., \& Tessier, R. (1989). Salivary IgA is a weak stress marker. Behavioral Medicine, 15, 179-185.

O'Leary, A. (1990). Stress, emotion, and human immune function. Psychological Bulletin, 108, 363-382.

Olness, R., Culbert, T., \& Donald, U. (1989). Self-Regulation of salivary Immunoglobulin A by children. Pediatrics, $\underline{83}, 66-71$.

Pennebaker, J., Kiecolt-Glaser, J., \& Glaser, R. (1988). Confronting traumatic experience and immunocompetence: A reply to Neale, Cox, Valdimarsdottir, and Stone. Journal of Consulting and Clinical Psychology, 56, 638-339.

Pennebaker, J., Kiecolt-Glaser, J., \& Glaser, R. (1988). Disclosure of traumas and immune function: Health implications for psychotherapy. Journal of Consulting and Clinical Psychology, 56, 239-245.

Pennebaker, J. W. (1982). The psychology of physical symptoms. New York: Springer-Verlag.

Pennebaker, J. W., \& Beall, S. K. (1986). Confronting a traumatic event: Toward an understanding of inhibition and disease. Journal of Abnormal Psychology, 95, 274-281.

Radloff, L. (1977). The CES-D Scale: A self-report depression scale for research in the general population. Applied Psychological Measurement, 1, 385-401. 
Rider M. S., Achterberg J., Lawlis, G. F., Goven A., Toledo, R., \& Butler, J. R. (1990). Effect of immune system imagery on secretory IgA. Biofeedback and SelfRegulation, 15, 317-333.

Rogosa, D. (1988). Myths about longitudinal research (pp. 171-208). In K. W. Schaie, R. T. Campbell, W. Meridith, S. C. Rawlings (Eds.). Methodological issues in aging research. New York: Springer Publishing.

Roitt, I. A. (1988). Essential immunology. Cambridge, MA: Blackwell Scientific Publications.

Scheier, M. F., \& Carver, C. S. (1987). Dispositional optimism and physical wellbeing: The influence of generalized outcome expectancies on health. Journal of Personality, 55, 170-205.

Scheier, M. F., Weintraub, J. K., \& Carver, C. S. (1986). Coping with stress: Divergent strategies of optimists and pessimists. Journal of Personality and Social Psychology, 51, 1257-1264.

Stone, A. A., Cox, D. S., Valdimarsdottir, H., \& Neale, J. M., (1987). Secretory IgA as a measure of immunocompetence. Journal of Human Stress, 13 , 136-140.

Stone, A. A., Cox, D. S., Valdimarsdottir, H., Jandorf, L., \& Neale, J. M. (1987). Evidence that secretory IgA antibody is associated with daily mood. Journal of Personality and Social Psychology, 52, 988-993.

Stone, A. A., Reed, B, \& Neale, J. M. (1987). Changes in daily event frequency precede episodes of physical symptoms. Journal of Human Stress, 13 , 70-74.

Tabachnick, B. G., \& Fidell, L. S. (1989). Using multivariate statistics (2nd ed.). New 
York: Harper \& Row.

Talbott, J. A., Hales, R. E., \& Yudofksy (1988). Textbook of Psychiatry. Washington, D. C: Americian Psychiatric Press, Inc.

Taylor, S. E., \& Brown, J. (1988). Illusion and well-being: A social psychological perspective on mental health. Psychological Bulletin, 103, 193-210.

Ursin, H., Reidar, M., Tonder, O., Vaernes, R., Relling, G., Isaksen, E., \& Murison, R. (1984). Psychological stress-factors and concentrations of immunoglobulins and complement components in humans. Scandinavian Journal of Psychology, 25, 340347.

Van Rood, Y. R., Bogaards, M., Goulmay, E. \& van Houwelingen, H. C. (1993). The effects of stress and relaxation on the in vitro immune response in man: $\mathrm{A}$ meta-analytic study. Journal of Behavioral Medicine, 16, 163-181.

Vela, M. (1990). The effect of humor on salivary immunoglobulin A in an adult population. Unpublished Master's Thesis, Florida International University, Miami.

Watson, D., Clark, L. A., \& Tellegen, A. (1988). Development and validation of brief measures of positive and negative affect: The PANAS scales. Journal of Personality and Social Psychology, 54, 1063-1070.

Weisse, C. S. (1992). Depression and Immunocompetence: A review of the literature. Psychological Bulletin. 111, 475-489.

Widman, F. K. (1989). An introduction to clinical immunology. Salem, MA: F. A. Davis Company. 
Yodfat, Y., \& Silvian, I. (1977). A prospective study of acute respiratory tract infections among children in a kibbutz: The role of secretory IgA and serum mmunoglobulins. The Journal of Infectious Diseases, 156, 26-30.

Zakowski, S. G., McAllister, C. G., Deal, M., \& Baum, A. (1992). Stress, reactivity, and immune function in healthy men. Health Psychology, 11, 223-232.

Zillman, D., \& Cantor, J. R. (1976). Effect of timing of information about mitigating circumstances on emotional responses to provocation and retaliatory behavior. Journal of Experimental Social Psychology, 12, 38-55. 


\section{NOTES}

1 The blood pressure meters were calibrated against a Carolina Sphygmomanometer ${ }^{\mathrm{TM}}$ (Nissei Manufacturing Company). Blood pressure readings on a subsample of six people were identical.

${ }^{2}$ Marginal baseline differences, while not significant at the .05 level, still existed, $\mathrm{E}(1,96)=3.35, \mathrm{p}=.07$. Subjects in the negative essay writing condition had higher levels of SIgA than subjects in the negative video viewing condition $(\underline{\mathrm{M}}=.34$ vs. $\underline{M}=.46$, Least Significant Difference (LSD) test $=.05$ ). It could be argued that an analysis of covariance, utilizing pretest scores as the covariate, is the proper statistic to use in order to minimize any source of bias created by pretest differences (Frijon \& Laurencell, 1993; Kirk, 1981; Tabachnik \& Fidell, 1989). However, if a particular study is interested in determining the degree of change due to some treatment, then either the use of change scores or a within-subjects repeated measures analysis is recommended (Tabachnik \& Fidell, 1989). To avoid any of the controversy that has been raised in the literature concerning the use of change scores (Cohen \& Cohen, 1989), a spit-plot mixed MANOVA, which incorporates both within and between subjects analysis was used in the present study. As Rogosa (1988) states: "The comparison of change across experimental groups is a standard, welldeveloped area of statistical methodology employing some form or repeated measures analysis of variance. When the effects of each treatment can be assumed identical for all members within each group (no individual differences in response to treatment), comparison of the parameters of the group growth 
curves yields inferences about the 'treatment effect' (p. 206)."

It should be noted that Cook and Campbell (1979) comment that randomly assigning subjects to conditions, as was done in this experiment, does not necessarily guarantee group equivalence.

${ }^{3}$ Pennebaker (1982) stated that although the emotions component of the SECL could be summed across items to create a total scale score, he uses the items in separate analyses in his own research. For the purpose of the present study, an emotions score was computed by summing across the four items in the SECL that formed the common factor scores. The single item, anxious, that formed an independent factor was analyzed separately. This method of analysis is the simplest means of interpreting, not only the effects of the manipulation, but the mediational effects of self-report affect on physical symptoms.

${ }^{4}$ Zakowski, McAllister, Deal \& Baum (1992) used baseline measures of distress as covariates when assessing the effects of mood manipulations on post manipulations measures of distress. Their rationale for these analyses was that baseline measures may bias post manipulation responses on affect measures. In the present study, covarying baseline measures of trait negative affectivity (as assessed by the negative affect subscale of the PANAS) from the two emotions factors yielded statistically significant between group differences for the conglomerate negative emotions factor, $\underline{F}(1,101)=4.54, \underline{p}<.05$. The overall MANOVA for the two emotions factors was not significant, and again, the univariate $\underline{F}$ test for the "anxious" factor was not significant.

5 As with the "emotions" scale, reliability analysis and factor analysis were 
conducted on the symptoms component of the SECL. All symptoms loaded on one factor,and item-total correlations did not yield any significant changes with the deletion of any items on the scale.

${ }^{6}$ Data for the present study was collected during the 8 to 17 week period following Hurricane Andrew. Because of this, several measures were included as covariates in order to statistically control for any effects the hurricane would have on physiological outcome measure. These measures included proximity to areas of major devastation, amount of stress incurred, and amount of property damage incurred. None of these measures significantly altered the main effect for method of induction on s-IgA when included as covariates in a MANOVA.

However, when proximity to areas of major devastation, stress, and property damage were included in a regression equation along with flow rate to predict premanipulation levels of SIgA, proximity achieved marginal significance, $\underline{t}=-1.68$, $\mathrm{p}=.10$ (Multiple $\mathrm{R}=.446, \underline{\mathrm{p}}<.001$ ).

Additionally, when proximity, stress, and damage were entered into a regression equation along with the personality predictors used in this study and flow rate to predict premanipulation levels of s-IgA, proximity was the most significant predictor, $\underline{\mathrm{t}}=-1.83, \mathrm{p}=.07$ (Multiple $\mathrm{R}=.491, \mathrm{p}=<.01$ ).

The above would indicate that the closer the subjects lived to areas of major hurricane damage, the lower were their s-IgA levels upon entering the laboratory. This relation, again, is marginal, and proximity did not interact with this study's manipulated variables. 
Appendix A

Personality Variables 


\section{Introversion-Extroversion/Neuroticism Scale}

Please fill in the appropriate space on the answer sheet an "A" for YES, or "B" for NO in response to the following questions.

1. Do you sometimes feel happy, sometimes depressed, without any apparent reason?

2. Do you prefer action to planning for action?

3. Do you have frequent ups and downs in mood, either with or without apparent cause?

4. Are you happiest when you get involved in some project that calls for rapid action?

5. Are you inclined to be moody?

6. Does your mind often wander while you are trying to concentrate?

7. Do you usually take the initiative in making new friends?

8. Are you inclined to be quick and sure in your actions?

9. Are you frequently "lost in thought" even when supposed to be taking part in a conversation?

10. Would you rate yourself as a lively individual?

11. Are you sometimes bubbling over with energy and sometimes very sluggish?

12. Would you be very unhappy if you were prevented from making numerous social contacts? 


\section{The PANAS}

This scale consists of a number of words that describe different feelings and emotions. Read each item and mark the appropriate answer (A, B, C, D, or E) on the answer sheet. Fill in the letter for the choice which describes to what extent you have felt that way during the past six months. There are no right or wrong answers. Please answer each question.
A - NOT AT ALL
B - A LITTLE
C - MODERATELY
D - QUITE A BIT
E - EXTREMELY

1. Interested

2. Irritable

3. Distressed

4. Alert

5. Excited

6. Ashamed

7. Upset

8. Inspired

9. Strong

10. Nervous

11. Guilty

12. Determined

13. Scared

14. Attentive

15. Hostile 
16. Jittery

17. Enthusiastic

18. Active

19. Proud

20. Afraid 


\section{Life Orientation Test}

Using the following scale, fill in the appropriate space on the answer sheet for the letter (A, B, C, D, or E) from the following scale which indicates how much you agree with the statements listed below.
A - STRONGLY AGREE
B - AGREE SOMEWHAT
C - NEITHER AGREE NOR DISAGREE
D - DISAGREE SOMEWHAT
E - STRONGLY DISAGREE

1. In uncertain times, I usually expect the best.

2. It's easy for me to relax.

3. If something can go wrong, it will.

4. I always look on the bright side of things.

5. I'm always optimistic about the future.

6. I enjoy my friends a lot.

7. It's important for me to keep busy.

8. I hardly ever expect things to go my way.

9. Things never work out the way I want them to.

10. I don't get upset too easily.

11. I'm a believer in the idea that "every cloud has a silver lining."

12. I rarely count on good things happening to me. 


\section{Dissipation-Rumination Scale}

Using the following scale, fill in the appropriate space on the answer sheet for the letter $(A, B, C, D$, or $E)$ which reflects your first reaction to each statement. Please do not leave out any item and be spontaneous and accurate as much as possible within the limits of choices offered below:
A - COMPLETELY TRUE FOR ME
B - FAIRLY TRUE FOR ME
C - TRUE TO A CERTAIN EXTENT
D - FAIRLY FALSE FOR ME
E - COMPLETELY FALSE FOR ME.

1. I never help those who do me wrong.

2. I will always remember the injustices I have suffered.

3. The more time that passes, the more satisfaction I get from revenge.

4. It is easy for me to establish good relationships with people.

5. It takes many years for me to get rid of a grudge.

6. When somebody offends me, sooner or later I retaliate.

7. I do not forgive easily once I am offended.

8. I often bite my fingernails.

9. I won't accept excuses for certain offenses.

10. I hold a grudge, for a very long time, towards people who have offended me.

11. I remain aloof towards people who annoy me, in spite of any excuses.

12. I can remember very well the last time I was insulted.

13. I am not upset by criticism.

14. I enjoy people who like jokes.

15. I still remember the offenses I have suffered, even after many years. 
16. If somebody harms me, I am not at peace until I retaliate.

17. When I am outraged, the more I think about it, the angrier I feel.

18. I like people who are free.

19. I am often sulky.

20. Sometimes I can't sleep because of a wrong done to me. 


\section{Center for Disease Control-Depression Scale}

Below is a list of the ways you may have felt or behaved at one time or other. Read each item and mark the appropriate answer $(A, B, C, D$, or E) on the answer sheet. Fill in the letter for the choice which describes to what extent you have felt or behaved this way during the past week. There are no right or wrong answers. Please answer each question.

A - NEVER (ZERO TIMES)

b - RARELY (LESS THAN ONE DAY)

C - SOME OR A LITTLE OF THE TIME (1 OR 2 DAYS)

D - OCCASIONALLY OR A MODERATE AMOUNT OF TIME (3 OR 4 DAYS)

E - MOST OR ALL OF THE TIME (5 TO 7 DAYS)

During the past week:

1. I was bothered by things that don't usually bother me.

2. I did not feel like eating; my appetite was poor.

3. I felt that I could not shake off the blues even with help from my family and friends.

4. I felt that I was just as good as other people.

5. I had trouble keeping my mind on what I was doing.

6. I felt depressed.

7. I felt that everything I did was an effort.

8. I felt hopeful about the future.

9. I thought my life had been a failure.

10. I felt fearful.

11. My sleep was restless.

12. I was happy.

13. I talked less than usual. 
14. I felt lonely.

15. People were unfriendly.

16. I enjoyed life.

17. I had crying spells.

18. I felt sad.

19. I felt that people disliked me.

20. I could not get "going". 
Appendix B

Informed Consent Form 
Informed Consent Form for

Participation in Psychological Research

\author{
James Rotton, Ph. D \\ Professor of Psychology \\ Susan Dubitsky \\ Graduate Doctoral Candidate \\ Florida International University \\ Health Psychology Study
}

I freely and voluntarily consent to be a participant in the research project entitled Health Psychology Study to be conducted at Florida International University during the summer semester, 1992, with Dr. James Rotton as Principal investigator.

I understand I will be paid $\$ 5.00$ when I complete the Health Psychology Study. My participation will require me to spend some time relaxing, then be exposed to emotionally arousing stimuli. I will also have to complete several questionnaires.

I am further aware that physiological measures will be collected. These physiological measures include saliva sample, blood pressure, heart rate and skin temperature. I understand that my saliva will be assayed for the presence of salivary immunoglobulin A. The experimenters will not assay my saliva for the presence of any drugs. Any and all information obtained from me will be kept completely confidential. My identity will be known only by an identification code number. My total time commitment will be approximately $11 / 2$ hours.

I understand that the purpose of this study is to see if my physiological responses relate to questionnaire data that was collected from me during the spring semester, 1992.

I understand I am free to leave and withdraw my participation at any time. I will, however, forfeit the $\$ 5.00$ fee if I don't complete the study.

Should I require any more information, I may call Dr. James Rotton, faculty supervisor, or Susan Dubitsky, at $940-5867$.

Sincerely yours,

James Rotton

Susan Dubitsky 
I have read the sheet entitled Health Psychology Study and understand what it says.

(name)

(social security number)

(date)

(address)

(city, state, zip)

(experimenter)

(instructor) 
Appendix C

General Health Inventory 
1. Excluding oral contraceptives, are you now taking a drug prescribed by a physician?
A. No
B. Yes, once a day
C. Yes, one or more times a day
D. Yes, one or more times a week
E. Yes, but infrequently (one or more times a month)

2. Are you now taking any nonprescriptive drugs (e.g., aspirins, cold tablets, antacid, cough syrup, remedy for constipation or diarrhea)?
A. No
B. Yes

3. During the past month, how may times have you visited a physician or your family doctor?
A. Never
B. Once
C. Two or three times
D. Four of five times
E. More than five times

4. During the past month, how many times have you been hospitalized?
A. Never
B. Once, a visit to an emergency or trauma center
C. Once, an overnight visit
D. More than once or for more than a day but less than a week
E. More than 7 days

5. How would you rate your health during the past week?
A. Very poor
B. Poor
C. Fair
D. Good
E. Excellent

6. During the past two week, how many days of school or work (including work around thee house) have you missed because you were not feeling well. Please write in your response: days

7. Have you experienced a change in your weight during the past month?
A. Yes
B. No 
8. Have you had an kind of infectious illness, such as a cold or the flu, illness within the past two weeks?
A. Yes
B. No

9. Have you been aware of having swollen glands within the past two weeks?
A. Yes
B. No

10. How many cups of coffee did you drunk during the past 24 hours? Please answer by completing the following sentence: I drank cups of coffee during the past 24 hours.

11. How many cola beverages (Coke, Pepsi, etc.) did you drink during the past 24 hours? Please answer by completing the following sentence: Excluding noncaffeine drinks, I have consumed the equivalent of 12-ounce cans of cola during the past 24 hours.

12. During the past three days, how many drinks of alcoholic beverages did you consume? By "drink" we mean five ounces of wine, 12 ounces of beer, or one ounce of whiskey? Please answer with a number:

13. How would you rate your health right now?
A. Very poor
B. Poor
C. Fair
D. Good
E. Excellent

14. Have any unusually upsetting events occurred to you in the past three days?

Y Yes

15. How many hours of sleep did you average during each of the past three 24-hour periods? less than four hours more than four hours but fewer than six hours more than six hours but fewer than eight hours more than eight hours but fewer than 10 hours more than 10 hours 
16. The following question is to be answered by women only:

What stage are you in your current menstrual cycle?

I don't know.

I've just gotten over my menstrual period.

I'm about midway in my menstrual cycle.

I'm anticipating my menstrual period

within a week.

I have my menstrual period now.

17. Are you a (check one)

day person

night person

both day and night person

neither day nor night person 
Appendix D

Suggested Topics for Mood Induction by Writing 
Listed below are some topics you may consider writing about. These are only suggestions. You may write about any negative [positive] experience you chose.

For Negative ruminations:

1. You don't have enough money to buy something you want, i.e., food, outfit, car, date.

2. Remember the last time your car broke down.

3. Remember the last time you had a deadline.

4. Thank about the last time you had or were in a car accident.

5. The last time you had a quarrel with someone important to you--parent, child, lover, spouse.

6. The last time you failed a test or did much poorer than you expected.

7. The last time you were a victim.

8. Your last job hassle wit a customer, boss, superior, co-worker.

9. Being conflicted over some kind of decision.

10. Wait in line.

11. Most traumatic experience.

12. Got sick or a family member got sick.

13. Justifiably angry.

14. Got dumped by someone you were dating. 
For Positive Ruminations

1. Got something you wanted

2. Were given a compliment

3. Find something you thought you lost.

4. Won something

5. Helped somebody

6. Came into money

7. Took a vacation

8. Went to your favorite place

9. Relaxed

10. Had Fun

11. Took a day off

12. Accomplished something you never thought you could do.

13. Flirted with someone you liked.

14. Found out someone you liked like you. 
Appendix E Video Rating Form 
Video:

Have you ever seen this video before today?

yes no

How did you feel about the video?

The video was...

$$
\begin{aligned}
& \operatorname{good} \overline{+3}: \overline{2}: \frac{1}{1} 0: \frac{1}{-1}: \frac{{ }_{-2}}{-3}{ }^{\mathrm{bad}} \\
& \text { boring } \frac{\text { : }}{+3}+\frac{:}{2+1}:-\frac{1}{-1}: \frac{:}{-2}: \text { interesting }
\end{aligned}
$$

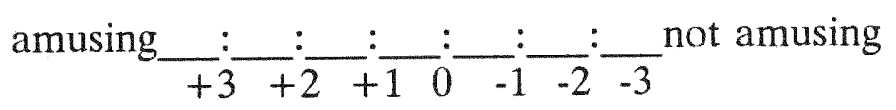

not entertaining $\frac{1}{+3}: \frac{:}{2}+\frac{1}{1}:-\frac{1}{-1}: \frac{2}{-3}$ very entertaining 
Appendix F

Symptom/Emotion Checklist 
Symptom/Emotion Checklist

Right now, at this moment, I am experiencing:

No headache Headache

No watering eyes Watering eyes

No racing heart

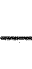

No congested nose

$-1$

No tense muscles $-1$

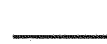
Tense muscles

No upset stomach Upset stomach

No flushed face Flushed face

No sweaty hands $-$ Sweaty hands

No shortness of breath

Shortness of breath

No cold hands Cold hands

No dizziness Dizziness

No ringing in ears Ringing in ears

Right now, at this moment, I am feeling:

Not happy

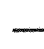

Not anxious

Happy Anxious

Not angry Angry

Not guilty<smiles>C=C</smiles>
Guilty

Not sad

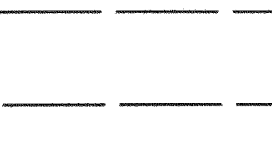

$-$ Sad 
Appendix G

Anonymous Evaluation of Research Assistants 


\section{Anonymous Evaluation of Research Assistants AD HOC COMMITTEE ON ETHICAL AND HUMANE STANDARDS}

This anonymous survey should be completed in private and then placed in the locked box at the door of the laboratory.

1.Are you in any way dissatisfied with the way you were treated in this experiment?

Not at all dissatisfied Extremely dissatisfied

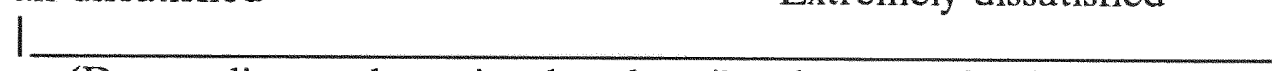

(Draw a line at the point that describes how you feel.)

2. Do you think the demands made upon you in this experiment were in any way excessive?

Not at all excessive

Extremely excessive

3. Were you in any way mistreated by the experimenter conducting this experiment?

Not mistreated at all

Mistreated to a great extent

4. How well did the student conducting this study perform the role of an experimenter?

Poorly

Excellently

5. How would you rate the assistant's manner of interacting with others?

Extremely discourteous

Extremely courteous

6. In your opinion should this student be reappointed as a research assistant?

Definitely not

Definitely yes

After completing this form, please place in an envelope, seal it, and drop the envelope in the locked box on your way out of the laboratory. Thank you. 
Appendix $\mathrm{H}$

Debriefing Form 


\section{Debriefing Form \\ Health Psychology Study}

Dear Study Participant,

Thank you for taking the time to participate in the Health Psychology Study. The study specifically concerns itself with how changes in mood relate to physiological responses. There is quite a bit of research that has demonstrated a link between mental states and immune functioning. Psychoneuroimmunology is the particular branch of psychology that concerns itself with studying the relation between mental states and the immune system. To date, there have been few laboratory tests that determined if mood actually causes physiological changes to occur. Consequently, you took part in an experimental procedure designed to affect people's moods. We wanted you to temporarily experience a good mood or a bad mood. Half of the people participating in this study had to write about positive or negative events that had occurred in their lives. The other half of the participants watched either a funny or a distressing videotape.

The study was designed to test the following experimental hypothesis: People who experienced a positive mood induction procedure will have higher salivary immunoglobulin A (SIgA) concentrations than subjects who experienced a negative mood induction procedure. As you may know, there is some reason to believe that SIgA is the body's "first line of defense" against the ravages of respiratory infections. Our aim has been to learn more about whether cognitive processes play a role in the production of SIgA. It is anticipated that our hypothesis will be supported.

If you would like to learn more about the field of psychoneuroimmunology, we'd like to recommend the following book (which is also very interesting and informative): Locke, S., \& Colligan, D. (1986). The healer within. New York: New American Library.

We would like to remind you that the information we have gathered is confidential and will be used along with data from other participants to describe general patterns and trends. If you have any questions at this time, the person conducting this experiment will do her best to answer them. If you would like to talk to me personally about any part of the study, you may call me at 940-5867.

Sincerely,

James Rotton, Ph. D.

Susan Dubitsky 
VITA

June 2, 1948 Born, Brooklyn, New York

EDUCATION:

1987

B.A., Psychology

State University of New York

College at Old Westbury 1987

1990

M.S., Psychology,

Florida International University

ACADEMIC HISTORY

1991 - Present: $\quad$ Graduate Adjunct Professor

Department of Psychology

Florida International University

1989 - 1991: $\quad$ Graduate Teaching Assistant

Department of Psychology

Florida International University

1988 - 1989: $\quad$ Graduate Research Assistant

Department of Psychology

Florida International University

\section{AWARDS AND HONORS}

American Psychological Association Dissertation Research Award, \$500.

State University of New York, College at Old Westbury - BA - Presidential Medal for Scholarship; 1987

PSI CHI (National Honor Society in Psychology) - Academic Excellence in Research; 1987

\section{RESEARCH GRANTS}

Dubitsky, S. \& Cutler, B. L. (1989). The contextual model of marriage revisited, FIU, College of Arts \& Sciences Minigrant Award, $\$ 750$.

Dubitsky, S. \& Rotton, J. (1992). The effects of heat and appraisal on salivary 
immunoglobulin A, FIU, College of Arts \& Sciences Minigrant Award, \$750.

\section{SCHOLARLY PUBLICATIONS}

Dubitsky, S., Weber, R. A., \& Rotton, R. J. (1993). Heat, hostility, and immune function: The moderating effects of gender and demand characteristics. Bulletin of the Psychonomic Society, 31, 534-536.

Dubitsky, S., Weber, R. A. \& Cutler, B. L. (under revision). The contextual model of marriage revisited. Journal of Social and Personal Relationships.

\section{CONFERENCE PRESENTATIONS}

Rotton, J., Milov, A., Dubitsky, S., Weber, R., \& Standers, B. (1994, March). The effects of a hurricane on an average population. Presented at Florida International University.

Rotton, J., Weber, R., \& Dubitsky, S. (1994, March). Lifestyles and expectancies of the rich and famous. Accepted for presentation at the Southeast Psychological Association.

Dubitsky, S., Weber, R., \& Rotton, J. (1993, June). Collection of saliva samples for biochemical assay: A comparison of methods. Presented at the American Psychological Society Conference, Chicago, IL.

Dubitsky, S., Weber, R., \& Rotton J. (1992, August). Effects of heat and cognitive appraisal on secretory immunoglobulin A. Paper presented at the annual convention of the American Psychological Association, Washington, DC.

Dubitsky, S., Weber, R., Makara, B., \& Fraser, S. (1991, August). The life enhancing effects of transpersonal practice, American Psychological Association, San Francisco.

Dubitsky, S., Weber, R. A., Fraser S. (1991, March). Functional flexibility in marriage, Southeast Psychological Association, New Orleans.

Weber, R. \& Dubitsky, S. (1991, March). Attributions in reciprocal and exchange relationships, Southeast Psychological Association, New Orleans.

Dubitsky, S. \& Cutler, B. L. (1990, August). The contextual model of marriage revisited, American Psychological Association, Boston.

Dubitsky, S. \& Cutler, B. L. (1990, March). The contextual model of marriage 
revisited, Florida International University, Miami.

Dubitsky, S. \& Martell, R. (1989, March). Effects of Alternate Nostril Breathing on Test Grades of College Students, Florida International University, Miami.

Dubitsky, S. \& Martell, R. (April, 1987). Effects of Alternate Nostril Breathing on Test Grades of College Students, Molloy College, Hempstead.

CONTINUING EDUCATION AND COMMUNITY OUTREACH

Stress and Time Management for City of Homestead Code Enforcement Employees - City of Homestead, Florida International University, Institute of Government, March 1994.

How to Motivate Yourself When You're Down: A Presentation for Florida State Town Clerks, Florida International University, February 1994.

Meeting the Challenge: Channeling Citizen Anger into Constructive Outlets: A Presentation for Town Clerks, Florida International University, February 1994.

Time Management for Broward County Code Enforcement Employees, Florida International University, Institute for Government, February 1994.

Stress Management for Broward County Code Enforcement Employees, Florida International University, Institute for Government, February 1994.

Stress Management for City of Miami Beach Code Enforcement Employees, Florida International University, Institute for Government, January 1994.

Stress Management for Unemployment Office Workers, Florida International University, Institute for Government, October 1993.

Stress Management for Unemployment Office Workers, Florida International University, Institute for Government, June 1993.

Stress Management for Code Enforcement Employees, Florida International University, May, 1993.

Giving up Anger and Resentment, Adoptee and Birthfamily Connection, Fort Lauderdale, Fl., April, 1993

The Survival Series, Posnack Jewish Community Center, Davie, Fl. October, 1992 
Stress Management for Code Enforcement Employees, Florida International University, May, 1992.

Stress Management for Code Enforcement Employees, Florida International University, Institute of Government, January 1992.

Surviving Interpersonal Relationships, Florida International University, Continuing Education, February-March 1990.

How to be More Creative, Florida International University, Elders Institute, February-March, 1990.

Surviving Interpersonal Relationships, Florida International University, Continuing Education, October, 1989

Stress Management, Lindenhurst H.S., Adult Education, 1985-1987.

Growing Younger Every Year, Glen Cove H.S., Adult Education, Spring, 1984.

How to be your own best friend, Merrick H.S., Adult Education, Fall, 1983. 